\title{
Estética e interpretación en el discurso literario La cueva de Montesinos de "Don Quijote"
}

Docente del Departamento de Literatura de la Universidad Nacional de Colombia

\section{RESUMEN}

Este artículo muestra la experiencia de lectura del discurso narrativo; en este caso, de la aventura de Don Quijote en la Cueva de Montesinos. Consta de dos partes: la primera es una exposición sobre los aspectos estéticos de la lectura del texto y la segunda lleva a cabo un recorrido textual por la aventura a través de uná propuesta de secuencias narrativas. Debido a que la aventura produce un efecto de simultaneidad y de multiplicidad de planos que fusionan realidad y ficción e historia y ficción, en el proceso de la lectura toma relevancia el diálogo entre el texto y el lector.

Durante la lectura se muestra una proximidad de la visión de Cervantes con las estéticas y la teoría literaria actuales que rompen con la concepción metafísica del lenguaje y lo abordan como discurso que deviene escritura, es decir, huella que se borra cada vez que se lee, en un proceso deconstructivo, determinado por la experiencia del tiempo humano. Esta caracterización exige una transformación en las estrategias pedagógicas para la lectura y la escritura en el aula a partir del texto literario.

\section{Palabras clave}

Discurso, lectura, ficción, narración, interpretación, deconstrucción, Quijote.

\section{ABstract}

This article shows the reading experience of the narrative discourse; in this case, this one of Don Quijote's adventure in Montesinos Cave. It consists of two parts: The first one is a presentation on the aesthetic aspects of the text reading and the second carries out a textual route by the adventure through a proposal of narrative sequences. The intention is to emphasize in the reading experience since the adventure produces an effect of simultaneity and multiplicity of plans (aspects) that puts into play aesthetic elements which integrate the reader with the relation between fiction and reality as well as history and fiction. In this sense, emphasis is made in the dialogue between the text and the reader in relation to the adventure reading process.

While the reading experience is being spun, other authors ideas appear related to those of Cervantes and allows the reader to pose theoretical- reflexive issues from the aesthetic and the literary theory that break up the metaphysical vision of the language and approach it as a discourse that becomes writing. It means, as a print that is erased once it is read, in a deconstructive process, determined by the experience of the human time. This characterization demands a transformation in the pedagogical strategies for the reading and the writing in the classroom from the literary text.

\section{KEY WORDS}

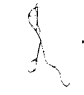

Words speech, reading, interpretation, deconstruction, Quijote . 


\section{Introducción}

$\mathrm{H}$ ay varios modos de entender la noción de cultura. Como "cultivo": un ideal cultural que debe ser perseguido según la valoración de los bienes culturales (legítimos vs. ilegítimos); como "acción": la posibilidad que tienen los actores sociales de renovar sus percepciones del mundo mediante la creación y el cambio; como "orden": la capacidad de la estructura social para mantener la regularidad del mundo mediante la preservación de una tradición y un patrimonio; como "estructuradora de la identidad", como "fuente de diversidad", como "recurso" económico y social, la cultura es un concepto de difícil aprehensión.

A pesar de tal dificultad no resulta extraño que, dependiendo de la empresa, se construya su concepto según los fines a alcanzar: las políticas culturales apelan hoy en día a la democracia y la diversidad, la economía de la cultura a la rentabilidad empresarial y el crecimiento económico de las naciones, la escuela a la preservación de la cultura y el cultivo de lo sancionado como culturalmente legítimo. Por esa misma vía, el propósito de este estudio es indagar cómo se construye ese concepto en las páginas culturales de los periódicos y revistas de circulación nacional: ¿Qué bienes simbólicos son divulgados en la prensa? ¿Qué se omite y a qué se le da visibilidad en las páginas culturales? Es decir, ¿cuál es la representación que los periódicos y revistas colombianas construyen sobre la cultura?

Aunque la prensa ha sido uno de los medios de comunicación más estudiados, gran parte del análisis se ha concentrado en algunas áreas: editorial, política, conflicto armado, seguridad y economía. No resulta extraño que los éstudios se interesen por las zonas duras de la prensa, especialmente en contextos como el nuestro. No obstante esa concentración, debe indicarse que los estudios culturales han ido desplazando las preguntas sobre la prensa hacia las zonas blandas, en particular si se piensa en los estüdios sobre los sectores populares y la llamada prensa sensacionalista. Los nombres de Sunkel y Fiske vienen a la memoria en casos como éstos. Sin embargo, y a pesar del interés creciente por lo popu- lar, el mundo del espectáculo y la televisión, es muy poco lo que se ha dicho sobre la cultura en la prensa o, de modo más preciso, sobre lo que la prensa ha etiquetado como cultura: las "páginas culturales", propósito del presente estudio.

Salvo críticas hechas al periodismo cultural (Martín-Barbero, 1991; Moreno-Durán, 1993; Zaid, 2006) o indagaciones teóricas sobre el oficio y la misión del periodismo cultural en un sentido normativo (Rivera, 1995; Barei, 1999; Villa, 2000; Esteinou, 1998), es difícil encontrar investigaciones que se apoyen en la recolección de material empírico. Sobresale en ese campo desolado un interesante estudio de García Canclini (2000) en el que se señala que aunque el tema de la cultura tiene cada vez más cabida en los diarios mexicanos, esa "expansión de la cultura no ocurre del mismo modo en las distintas secciones de los periódicos" debido a los "diversos modos de organizar lo local, lo nacional y lo global en distintos campos culturales": lo global en espectáculos, economía e informática; lo nacional y lo local en la sección titulada "cultura", dedicada en gran parte a los bienes culturales de la "alta cultura". No obstante lo interesante de los resultados, resulta inquietante la utilización de las variables "alta cultura" y "cultura popular", después de que el autor ha teorizado sobre hibridaciones (1990) y ha llamado a la reserva frente a las concepciones jerárquicas de la cultura (2004). Ahí la distancia entre teoría y categoría empírica hace cortocircuito.

\section{Multiplicidad y simultaneidad de la ficción}

\section{La apertura de la caverna como una experiencia de lectura}

\section{Contextos y perspectivas}

Se ha elegido esta aventura del Quijote porque dentro del conjunto de la obra tiene un carácter integrador y permite pensar la problemática del diálogo entre el texto y el lector como acontecimiento interpretativo desde el discurso narrativo. 
La narración de este evento en el texto cervantino genera una lectura múltiple y simultánea que transforma la concepción lineal de lo histórico ${ }^{1}$. Esto significa que el discurso narrativo rompe la secuencia temporal y pone en juego una perspectiva del tiempo de carácter abierto circular que articula el pasado, el presente y el futuro en el instante ${ }^{2}$. Este asunto es central para las reflexiones contemporáneas sobre el lenguaje y la literatura. La intención es mostrar cómo, al seguir el' discurso, se abre esta simultaneidad temporal que a su vez configura relaciones entre diversos planos de realidad. El espacio y el tiempo se diseminan por muchos espacios y tiempos que a la vez emergen a medida que se sigue la trama de los acontecimientos. La prioridad está en la manera como en la conciencia del lector va surgiendo este tejido de planos espacio temporales que exigen un lector de lo simultáneo y lo múltiple; entonces, la estructura narrativa se "historiza".

Este efecto de lectura muestra la importancia del Quijote en las reflexiones contemporáneas sobre el lenguaje y la cultura porque da indicios sobre cómo se fue desbordando la visión metafísica del mundo. En Cervantes, ese mundo ideal que fundamenta este mundo ilusorio del devenir pierde su carácter de permanencia y se resquebraja debido a que también se vuelve ilusorio en la trama narrativa de orden ficticio que logra construir el autor. Este hecho provoca un giro significativo respecto de la concepción metafísica del lenguaje que sólo lo asume como instrumento para expresar lo que sucede en la interioridad ideal de un sujeto.

Este mismo efecto lo padece el lector quien, al entrar en la cueva de Montesinos, siente la confusión de los mundos que simultáneamente sa-

1 E1 artículo: "Genre Definition and Multiplicity in Don Quixote", de Anthony J. Cascardi, desarrolla algunos. aspectos de esta problemática.

2 Ricoeur, con el apoyo en Heidegger, establece la relación entre tiempo y narratividad; en consecuencia, el tiempo humano se despliega en tres dimensiones profundas: temporalidad, historicidad e intratemporalidad (1999 a y 1996). Del mismo modo, en el texto sobre triple mímesis, en la que expone los tres momentos de la lectura: prefiguración, configuración y refiguración, se experimenta esta multiplicación del tiempo cuando tiempo y narración interactúan (1987a).

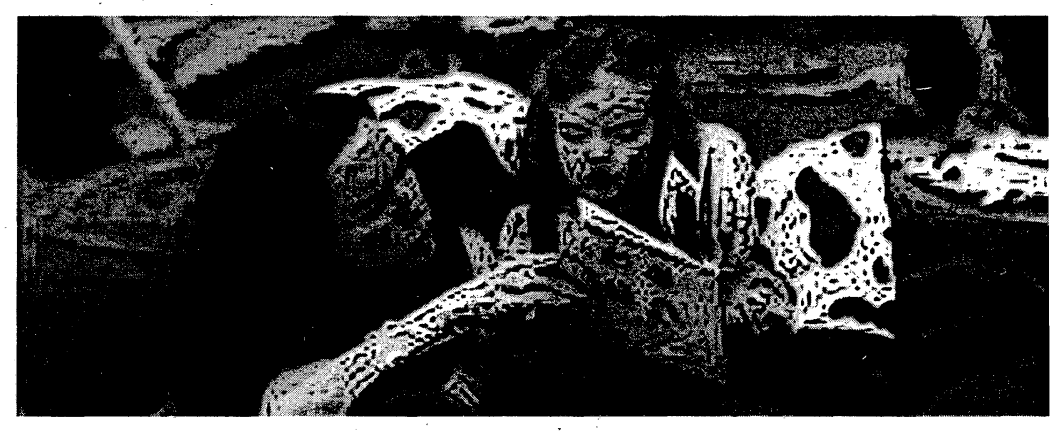

len a su encuentro. Entonces, los personajes de la historia, Don Quijote, Sancho y el primo, como ficciones de la obra, entran a un ámbito en el que encuentran otros personajes ficticios del pasado. Entonces, allí, los tiempos se fusionan y se produce una trama de realidades simultáneas. A su vez, el lector, en su proceso de lectura, se encuentra en ese mundo de ficciones entrelazadas y, a través de las marcas del texto, ingresa también como ficción a ese universo de simultaneidades.

Este acontecimiento tiene que ver con una poética de la lectura que se va generando a medida que el lector fenoménicamente va imaginando la acción, los personajes, los lugares, los símbolos. "Cervantes crea el espacio de la cueva de Montesinos, un espacio donde lo verosímil tiene una importancia estética independiente de la historia, de la fábula y de la metafísica. El simbolismo propio de ese espacio genera en el lector el escenario en el cual transcurren las complejas interrelaciones entre personajes" (Núñez, 2003).

Esto sucede porque el texto cervantino crea un entramado que provoca dicha ambigüedad y porque el lector responde a dicha ilación discursiva. Por tanto, la hipótesis es que desde la actualidad se lee con mayor fluidez este texto de Cervantes, porque está escrito precisamente para lectores contemporáneos ${ }^{3}$, quienes están inmersos

3 Esto, además, significa que los niños y los jóvenes, a diferencia de las apreciaciones generalizadas que circulan en la escuela, tienen mayor disposición cultural a esta obra y, por tanto, a las obras clásicas, porque en ellas siempre se da un juego de multiplicidad, equivalente, en ciertos rasgos a la hipertextualidad e intertextualidad contemporánea. En consecuencia, es decisivo atender a estas implicaciones pedagógicas cuando llevamos los textos literarios al aula. El artículo quiere impulsar el proceso fenomenológico, vivencial, de la lectura, porque ahí se fortalece el gusto por la lectura, la comprensión y la crítica en los niños. 
en el mundo de los hipertextos, de la textualidad y de la intertextualidad. Lo sucedido en la obra, antes y después de esta aventura, acentúa este carácter múltiple, puesto que al despertar, Don Quijote no resuelve la ambigüedad porque no dice si fue un sueño o un hecho real aquello que vio en la cueva.

De otro lado, no sabemos si lo contó Don Quijote, Cervantes, Cide Hamete, Alonso Quijano; esto provoca un juego de simultaneidad del discurso, llevado a su máxima expresión en este episodio, que hace necesario un replanteamiento de las concepciones de lo real, del pasado y del presente y, por tanto, del lenguaje, de la lectura y del lector. De esta forma, el lector actualiza el texto desde su propia experiencia cotidiana. Esta proximidad de la obra lo impulsa, a su vez, a leer su propio entorno mundano con intenciones estéticas, políticas y éticas propias. En suma, puede afirmarse que la obra de Cervantes, a la luz de la lectura de esta aventura, produce lectores críticos que logran construir su propia perspectiva cuando reconocen las múltiples perspectivas de mundo que hoy se entretejen en simultaneidad, sean de orden cultural, religioso, político, artístico, en fin.

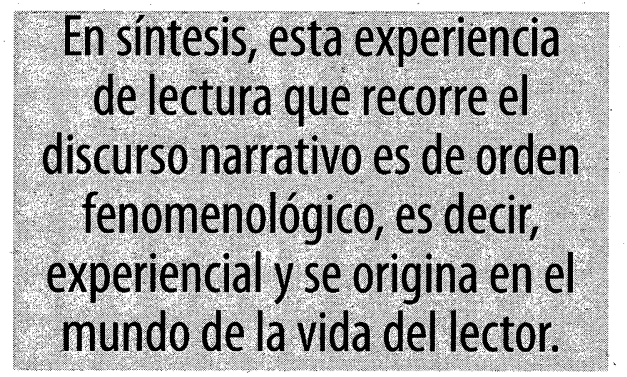

Para explicitar este efecto de lectura se tienen en cuenta los siguientes aspectos: la relación entre estética y fenomenología en el proceso de lectura, la relación entre el tiempo de la narración y el tiempo experimentado por el lector y la destrucción de la dicotomía que Platón establece en el mito de la caverna.

En síntesis, esta experiencia de lectura que recorre el discurso narrativo es de orden fenomenológico, es decir, experiencial y se origina en el mundo de la vida del lector. De otro lado, en esta aventura de Don Quijote, la lectura fluye en el tiempo que corresponde al tiempo del lector, pero como el acontecimiento se va tejiendo desde lo ficticio, se produce una destrucción de la experiencia platónica del mundo en la caverna de las sombras. En el caso del Quijote, el lector se va perdiendo en ellas y no necesita buscar la luz fuera de la caverna. $\mathrm{El}$ proceso se invierte y cada vez el lector se ve más abrumado por las sombras, pero también por la iluminación de lo eterno que se trasluce en la historia de Durandarte, de Merlín y de Belerma, sin necesidad de salirse de esa oscuridad porque todo se halla en el juego sensible de la ficción. Como allí vuelve a aparecer Dulcinea, el lector debe agudizar sus sentidos para reconocer la interpenetración de planos. En estas condiciones ni el lector ni el Quijote encuentran un mundo distinto al de la caverna para explicar dichas experiencias. Con esto se ha iniciado otro modo de leer que es de carácter dialógico porque a la vez que deja al lector inmerso en el mundo de la ficción lo envía hacia su experiencia en el mundo de la vida, pero con una mirada ampliada para reconocer la multiplicidad y la simultaneidad en la propia cotidianidad de su devenir.

\section{Estética y fenomenología de la lectura}

Ésta es una experiencia de lectura que parte de dos principios interpretativos: el encuentro estético, sensible, con el texto y el ir recorriéndolo tejido a tejido. Por tanto, ésta es una interpretación proposición tras proposición, secuencia a secuencia. La intención es ir abriendo en el discurso el significado y las conexiones con otros textos y otras ideas, en particular con las teorías interpretativas y las estéticas contemporáneas. En este sentido, el texto de Cervantes, y particularmente el capítulo XXIII de la segunda parte, deja realizar esta experiencia de lectura porque produce una ruptura de la continuidad a medida que abre la multiplicidad desde cada detalle: objeto descrito o hecho narrado. Este modo de recorrer el texto exige un lector de lo simultáneo como ha de ser el lector de hoy. Por eso, el propósito aquí es seguir el texto como si se entrara en una caverna donde la penumbra vuelve impreciso y ambiguo todo. Lo que se halla allí parece ilusorio pero materializado y entrelazado por una invisibilidad y una transparencia que se impregna en las huellas oscuras de la página blanca. En este sentido, María Gracia Núñez, en "Ilusión 
y realidad en la cueva de Montesinos del Quijote", afirma: "Es así que podemos observar que el autor juega con la verosimilitud de los personajes y también con la verosimilitud referida al lector. Por ejemplo, mientras Cervantes proporciona datos aparentemente contradictorios, pregunta acerca de si se trata de un sueño o de una invención lo acontecido dentro de la cueva, êl lector deberá averiguar si es cierto o no, lo que le sucede a don Quijote dentro de la cueva de.Montesinos":.

En esta manera de leer se nos va el tiempo ${ }^{5}$; o nos vamos en el tiempo, corroídos por la desproporción de la palabra del poeta; en este caso de Cervantes. El tiempo y la narración (Ricoeur, 1999) van coincidiendo en un paralelismo que se aproxima y aleja. Todos los tiempos se funden con el tiempo del lector. Incesantemente se crea y se destruye la temporalidad en el discurso narrado.

En este pasaje se ha producido una inversión histórico-estética. La caverna platónica gira en un sentido contrario, de ahí que la temporalidad también se transforma. La contemplación se vuelve percepción, lo inteligible pierde su fundamento y se vuelve eternidad efímera, ilusión de ilusión, sombra de sombra. El filósofo no necesita ascender para reconocer la luz de la verdad; más bien, transformado en personaje de la ficción, en Don Quijote, desciende al espacio cristalino de la "eternidad móvil" (Borges I, 2001), al lugar de la muerte que se mueve permanentemente muriendo. Un descenso que cada vez se vuelve ascenso, una desmaterialización en la materia. Por estos motivos, la cueva de Montesinos es la hendidura de la obra de Cervantes, por tanto, la quebradura de la modernidad.

\section{Las contradicciones y las ambigüedades de las sombras}

En la apariencia que deja traslucir la esencia, el sueño provoca alucinaciones precisas. Este es el

4 (C) María Gracia Núñez 2003. Espéculo. Revistả de estudios literarios. Universidad Complutense de Madrid. E1 URL de este documento es http://www.ucm.es/info/ espéculo/numero24/cervante.htmle

5 Heidegger y Ricouer lo denominan "intratemporalidad": contar con el tiempo; estar en el timpo. carácter poético del texto cervantino: un juego irresoluble que hace ver lo que no es y hace de lo que es pura aparición. En esta interacción se ha roto la dicotomía entre ser y apariencia mediante el sueño y la locura. El entrelazamiento de realidad y sueño y de locura y razón despejan el abismo de lo inconsistente; de ahí surge la escritura borrada que se lee por entre los resquicios de lo blanco ${ }^{6}$. El más mínimo detalle, como la apariencia nervosa de la mano derecha de $\mathrm{Du}^{-}$ randarte o los dientes separados de la señora Belerma ${ }^{7}$, recoge el destello fugitivo de la eternidad. Por tanto, mirar lo sensible es experimentar lo inteligible. Esta dialéctica poética rompe el discurso cartesiano y, por tanto, pone en paréntesis, como lo dice la fenomenología de Husserl (1985), la racionalidad moderna occidental.

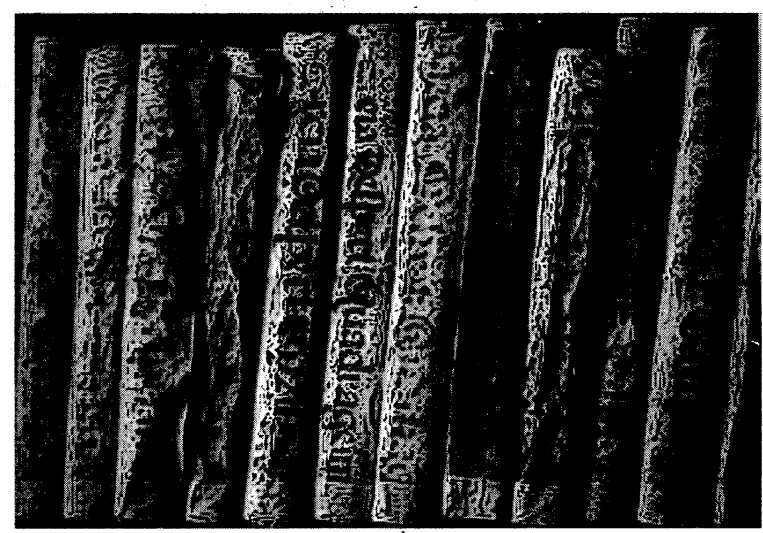

Esta desconexión del mundo de lo dado abre el universo de la imaginación, pero sin desprenderse de las cosas mismas, porque ellas emergen en el sueño tal y como son, como sombras y, por tanto, como realidades. En este efecto fenoménico de irrealización se fractura la historia porque la separación entre lo imaginario y lo real desaparece. Se produce una ambigüedad que consiste en que en el "aparecer" de lo que existe se trasluce lo que "es". En consecuencia,

6 Éste es el carácter no metafísico de la escritura, desarrollado por Derrida en sus textos: una marca escritural que se ensordece, una Diffèrance (1989).

7. Meter N. Dunn hace algunas apreciaciones sobre la fisonomía de la Señora Belerma y sus relaciones con lo onírico, lo histórico y el carácter moral del personaje. También es importante el texto de Helena Persas sobre este personaje. 
Cervantes prefigura la época posmetafísica de la diferencia y de la intertextualidad en la que la escritura libera al libro de la metafísica de la presencia y de la teología del fundamènto. Aquí la dicotomía entre ser y apariencia y entre lenguaje y concepto se anula. Esto significa que el mundo de la eternidad se fragmenta y deja de ser principio explicativo de este mundo de lo sensible. Por tanto, experimentar esta fractura es leer estos mundos como escritura duplicada.

\section{La escritura, la imaginación y la eternidad}

Esta aventura del Quijote permite comprender la ruptura contemporánea. El "libro" de la metafísica se ha resquebrajado $y$ sus fragmentos se interconectan en una dispersión atenuada en la que todo se entrecruza. Como se ha perdido la jerarquía entre lo soñado y lo real, todo aparece en simultaneidad, pero bajo ùna figuración concreta. Las cosas se entrechocan y conforman mundo, tejido, conexión. Lo que las une se esfuma en ese aparecer, como una huella que se silencia: "Siempre difiriendo, la marca no está nunca como tal en presentación de sí. Se borra al presentarse, se ensordece resonando, como la A (de la palabra Diffèrance) al escribirse, que inscribe su pirámide en la diferencia" (Derrida 1989,57).

Todos los planos de la realidad instauran un juego de reflexión especular. Se cruzan unos sobre otros, unos detrás de otros, unos dentro de otros. Todo deviene texto narrado, texto de ficción que a su vez se funde con el texto real. Y esos nodos de conexión multiplican las diferencias. Se genera una ambigüedad que se reproduce en el infinito. Ésta es la experiencia poética de lectura de esta aventura del Don Quijote; en ella todo emerge en simultaneidad y desde múltiples perspectivas. En consecuencia, para hacer una lectura consistente, es necesaria la toma de distancia. Al hacerlo, el lector reconoce que está entrelazado textualmente con la obra e históricamente determinado por la realidad. De modo que esta obra, como toda obra de arte, produce, ella misma, el distanciamiento: el lector se ve inmerso en medio de lo simultáneo, de lo múltiple $\mathrm{y}$ de lo diferente, pero reconoce que interactúa desde su propia perspectiva que es distinta a las otras y que se configura desde su propia interrelación con el mundo que ahora ha tomado distancia de lo dado.

Este efecto textual produce la diferencia que rompe la dicotomía de la dialéctica racional. $\mathrm{El}$ juego de interrelación entre lo real y lo imaginario se produce mediante el juego de diferencias: lo real es real e imaginario a la vez y lo imaginario es, del mismo modo, real e imaginario a la vez. Entonces, situarse en lo imaginario es corresponder a lo real y corresponder a lo real es situarse en lo imaginario. En este sentido, se produce una ambigüedad como si el mundo fuera un juego de sombras. En él las cosas son ellas mismas, las sombras, y las sombras, las cosas. Ninguna produce la otra; la sombra es de por sí imaginaria, pero es de lo real y lo real produce sombras, pero es imposible ver sombras de algo que no sea real y al contrario. De esta forma, se ha diferido la dicotomía platónica que separa mundo sensible y mundo inteligible, mundo de la opinión y mundo de la verdad, y con ello la concepción platónica de signo como relación entre significante y significado se ha deconstruido. Así, esta diferencia se vuelve escritura. Esto lo muestra Derrida en $D e$ la gramatología:

El advenimiento de la escritura es el advenimiento del juego: actualmente el juego va hacia sí mismo borrando el límite desde el que se creyó poder ordenar las circulación de los signos, arrastrando consigo todos los significados tranquilizadores, reduciendo todas las fortalezas, todos los refugios fuera-de-juego que vigilaban el campo del lenguaje. Esto equivale, con todo rigor, a destruir el concepto de signo y de toda su lógica. Sin lugar a dudas, no es por azar que este desbordamiento sobreviene en el momento en que la extensión del concepto de lenguaje borra todos sus límites (12).

Se genera la diseminación textual. La aventura es un significante de un significante, es la escritura de Don Quijote que se vuelve texto ambiguo: ni significante ni significado. $\mathrm{El}$ sentido se disemina por todas las regiones del texto como sombras que se escriben cada vez indefinidamente. El libro se rompe, pierde su autonomía, y se 
crea el tejido de diferencias ${ }^{8}$. De modo que en un efecto de diseminación la eternidad se vuelve móvil, como si en cada situación o en cada instante se creara esa eternidad y a la vez se destruyera. En consecuencia, no es una eternidad perdurable sino instantánea, rota, quebrada, inestable, en últimas, móvil. Esto quiere decir que el libro se ha diluido como texto, que el lenguaje se ha diseminado como marca de escritura. En estas condiciones no es posible distinguir el significado del significante ${ }^{9}$ porque han recobrado su proximidad y su diferencia.

A su vez, la lectura debe corresponder a esa diseminación textual. Al revés que en la caverna platónica, en esta caverna imaginaria la escritura no es simulacro de simulacro no verdadero, ni está alejada cuatro veces de la realidad eterna de las ideas; más bien, integra en su diseminarse las ideas como acontecimientos instantáneos, a manera de discurso, como simulacro de simulacro que no depende de su verdad o de su esencialidad. Por tanto, la experiencia que sigue muestra un recorrido por las diseminaciones de la eternidad en la cueva de

8 Para Derrida, la interconexión infinita es como un haz de relaciones: "Por otra parte, la palabra haz parece más propia para poner de manifiesto que la agrupación propuesta tiene la estructura de una intricación, de un tejido, de un cruce que dejará partir de nuevo los diferentes hilos y las distintas lineas de sentido (o de fuerza) igual que estará lista para anudar otras" $(1989,40)$.

9 De ahí los visos metafísicos del capítulo de Helena Percas sobre la cueva de Montesinos en Cervantes y su concepto de arte; se mantiene una concepción del lenguaje como expresión de un estado metafísico del sujeto: "Del episodio de la cueva de Montesinos, Cervantes hizo un espejo de la vida interior. Su invención genial fue construir una alegoría de la naturaleza humana, libre de la limitación o desvirtuación del punto de vista, el cual parte de un arsenal de precomprensiones. El arte... proyecta realidades interiores si coincide con la naturaleza humana" $(1975,446)$. Desde otra perspectiva, aquí se insiste en la ruptura de ese mundo interior subjetivo a través de una visión del lenguaje que desborda la dicotomía y que se vuelve discurso que es leído por un lector quie lo actualiza en su temporalidad y que entra en juego con la simultaneidad temporal de la aventura. La idea de texto, tanto de Gadamer como de Ricouer, desarrolla esta visión diferente. Sin embargo, esto no significa que la lectura de Percas no sea válida, se hace bajo otro enfoque. En mi libro Ensoñaciones, escrituras, tejidos. Debates Bachelard-Derrida (2003), amplío esta problemática sobre la escritura.
Montesinos, donde unas sombras ambiguas se tejen como escritura simultánea.

Bajo estos presupuestos, el rastreo sobre los artículos ${ }^{10}$ que hacen referencia a esta aventura ha servido pàra afianzar aún más esta perspectiva. Estas propuestas de lectura se centran en el libro de Cervantes; en sus problemáticas y en las conexiones que allí se dan, pero no se orientan hacia el proceso de lectura textual y el efecto de irrealización del lector cuando se enfrenta a esta aventura, que es un ejemplo magistral del discurso literario como júego textual. Por ello, en estos autores aún no aparece una reflexión significativa sobre este encuentro entre el mundo del texto y el mundo del lector ${ }^{11}$. Por eso es necesario recurrir a la estética contemporánea y a las tendencias interpretativas y deconstructivas actuales que abordan el texto literario desde una perspectiva que rompe con la metafísica platónica en la que la escritura es apenas impresión sensible mentirosa que no porta en sí la verdad de las ideas, sino que es puro reflejo de un modelo eterno y perfecto que se halla en el mundo iluminado por la idea de las ideas o que depende del libro cerrado que las sustenta y de la subjetividad del personaje o del autor.

${ }^{10}$ Los artículos que se refieren a la aventura dedican pocas referencias a este tópico de la lectura. Pero ideas como las de multiplicidad, intertextualidad y efectos estéticos están presentes en estos textos. Algunos de ellos han sido tomados de la base de datos de Jstor, son: "Un momento de la creatividad cervantina en el Quijote: los capítulos XVIII-XXIII de la segunda parte”, de Raimond R. Maccurdy, Alfred Rodríguez; "La cueva de Montesinos por fuera y por dentro: Estructura épica, Fisonomía", de Meter N. Duna; "Literary Time in the "Cueva de Montesinos". Harry Sieber. "La cueva de Montesinos" y "Unas palabras más sobre Belerma (Quijote II, 23)", de Helena Percas de Ponseti; "Symbolic Action in the Episode of the Cave of Montesinos from "Don Quijote", de Gloria M. Fry; "The Cave of Montesinos", de Joseph G. Fusilla.

${ }^{11}$ Algunos artículos hacen referencia a esta relación, pero no en particular sobre esta aventura del Quijote, por ejemplo, en “José María Paz Gago's, Semiótica del Quijote: Teoría y práctica de la ficción narrativa", de James A. Parr; en "Ring Around the Hermeneutic Circle", de Edward Dudley o en "Narrador, the reader and Don Quijote", de Johin J. Allen. 


\section{El camino de la interpretación textual}

Desde estos criterios estéticos se hace esta interpretación de la aventura de la Cueva de Montesinos de Don Quijote momento a momento. A1 seguir la aventura, el lector entra en ese ámbito de lo múltiple, proposición tras proposición, escritura tras escritura; se hunde en el devenir del discurso que es el mismo devenir del lector y el mismo decurso de la acción. Ricoeur lo define de este modo: "Considero que la temporalidad es una estructura de la existencia - una forma de vida- que accede al lenguaje mediante la narratividad, mientras que ésta es la estructura lingüística -el juego de lenguaje- que tiene como último referente dicha temporalidad. La relación, por tanto, es recíproca" $(1999,183)$. De este modo, el lector prefigura, configura y refigura el texto y se deja ir en su propia temporalidad. Lo que sigue es un ejercicio expositivo que indica cómo se va experimentando esa temporalidad discursiva. En primer lugar, es necesario determinar las secuencias narrativas de la aventura para ir avanzando en la experiencia de lectura, guiados por la arquitectura del texto:

\section{Las secuencias narrativas}

Este texto puede dividirse en las siguientes se secciones narrativas, que en secuencia son:

1. Comienzo de la aventura

2. La caverna de la imaginación

3. Enigma y eternidad del encantamiento

4. La canción del encantado

5. Encuentro de historias, aproximación de planos y personajes: Belerma y Dulcinea

6. Entre la realidad y la ficción, entre la mentira y la verdad, entre lo actual y lo pasado

7. Las labradoras: el encuentro de las ficciones

8. Dulcinea encantada

9. Entre la locura y el sentido

10. Retorno al plano de la narración primaria

Esta propuesta de estructura narrativa responde a un criterio generado en el diálogo entre el texto y el lector. A medida que se avanza en la lectura van apareciendo diversos horizontes interpretativos y algunas referencias a otros textos, sean de orden teórico, filosófico o literario. Se trata de mostrar cómo la lectura de esta aventura produce estas aperturas hacia lo múltiple en las que se interconectar otros textos. Otro lector puede seguir otro camino.

\section{Segunda parte del ingenioso caballero don Quijote de la Mancha}

\section{Capítulo XXIII}

\author{
De las admirables cosas que el extremado \\ don Quijote contó que había visto en la profunda \\ cueva de Montesinos, cuya imposibilidad y grandeza \\ hace que se tenga esta aventura por apócrifa.
}

\section{El comienzo de la aventura}

La aventura comienza con una ubicación espaciotemporal:

Las cuatro de la tarde serían, cuando el sol, entre nubes cubierto, con luz escasa y templados rayos dio lugar a don Quijote para que sin calor y pesadumbre contase a sus dos clarísimos oyentes lo que en la cueva de Montesinos había visto; y comenzó en el modo siguiente (590):

\section{La caverna de la imaginación: la ruptura del mundo inteligible}

Los sucesos de esta primera sección son en su orden: Se describe la caverna como una mazmorra con luz escasa, el narrador expresa la certeza de si como soñador, la acción sucede en el palacio de cristal, abi se ve el corazón de Durandarte y el puñal; finalmente el primo invita a proseguir la historia.

Se abre el texto y se despliega la página como una puerta, ya el lector ha comenzado la aventura. El relato toma un tono irreal y subterráneo. El olor a eternidad irrumpe e invade la respiración y las imágenes se cuelan como sombras. Con la rememoración de las aventuras previas, y dispuesto a asombrarse, el lector se de- 
tiene en medio de. esta grieta textual: la aventura de la cueva de Montesinos. Una elección que desde el punto de vista estético produce un sentimiento de lo sublime por lo abismal e imaginario del suceso. Las facultades del entendimiento y la razón entran en choque. Esta conmoción anímica que se padece al leer esta aventura se experimenta durante la lectura de todo el Quijote. La primera visión de la caverna confunde y desestabiliza el espíritu. Se advierte lo que dice Kant:

...en cambio, lo que despierta en nosotros, sin razonar, sólo en la aprehensión, el sentimiento de lo sublime, podrá parecer, según su forma, desde luego, contrario a un fin para nuestro Juicio, inadecuado a nuestra facultad de exponer $y$, en cierto modo, violento para la imaginación; pero sin embargo, sólo por eso será juzgado tanto más sublime $(1984,164)$.

La luż que penetra por la hendidura es la señal de que ha comenzado el viaje por la arquitectura ficticia del lenguaje de Cervantes: "Éntrale una pequeña luz por unos resquicios o agujeros, que lejos le responden, abiertos en la superficie de la tierra". Hay una extraña semejanza con la caverna platónica:

-Ahora represéntate el estado de la naturaleza humana, con relación a la ciencia y a la ignorancia según el cuadro que te voy a trazar. Imagina un antro subterráneo, que tenga en toda su longitud una abertura que dé libre paso a la luz, y en esta caverna hombres. encadenados desde la infancia, de suerte que no puedan mudar de lugar ni volver la cabeza a causa de las cadenas que les sujetan las piernas. y el cuello, pudiendo solamente ver los objetos que tienen enfrente. Detrás de ellos, a cierta distancia y a cierta altura, supóngase un fuego cuyo resplandor los alumbra, y un camino escarpado entre este fuego y los cautivos. Supón a lo largo da este camino un muro, semejante a los tabiques que los charlatanes ponen entre ellos y los espectadores, para ocultarles la combinación y los resortes secretos de las maravillas que hacen (Platón 1984, 205).
Sin embargo, ya presentimos que se trata de un descenso y no de un ascenso; de un extravío en el mundo sensible. ¿Acaso Cervantes no hace desde su tiempo la ruptura posmetafísica? Le ha dado vuelta a la caverna platónica y los mundos se han trastocado. ¿Acaso no ha sido nietzscheano antes de Nietzsche y ha tomado, en una misma época, un camino distinto al de Descartes? Por esto, Cervantes es centro de las rupturas históricas en el pensamiento y la literatura de Occidente; por un lado, provoca la inversión de la caverna platónica $y$, a la vez, a partir de ello, aproxima narración y pensamiento. Estos dos aspectos son los que hoy caracterizan el pensamiento contemporáneo: la ruptura con el platonismo y la aproximación entre el pensar y el poetizar (Heidegger). Desde estas consideraciones, Cervantes parece adelantarse al aforismo de Nietzsche "De cómo el 'mundo verdadero' se convirtió en fábula”, de El crepúsculo de los ídolos:

Nos deshicimos del mundo verdadero. ¿Cuál nos queda? ¿Quizás el aparente? ¡No, no! $¡$ Con el mundo verdadero nos deshicimos también del mundo aparente! (III, 1190).

Ahora el camino hacia arriba es el camino hacia abajo, entre sombras, entre simulacros. Lo aparente es, tanto lo inteligible como lo sensible, la luz y la oscuridad, la vida de arriba y la vida de abajo. No se puede diferenciar esta duplicidad de mundos. Don Quijote desciende, pero este descenso le aproxima lo que se halla arriba.

¿Cuál es ese hilo de conexión de los dos mundos?: una soga. $\mathrm{Y}$ en mitad del descenso Don Quijote se recoge para pensar su propia caí$\mathrm{da}$, se halla al borde de una frontera que lo conducirá a la más próxima eternidad. El hilo de luz platónico se vuelve una burda y delgada cuerda de sostenimiento.

La sensación de descenso es pavorosa, Don Quijote no sabe si ir al fondo, se siente suspendido en un vacío incomprensible. Se despliega en el relato un sentimiento terrorífico de soledad: un hombre colgando de una cuerda frágil, próximamente mortal. Sin embargo, en el momento más riesgoso y peligroso se hunde en el sueño y en un lapso breve de la narración, en un instante imperceptible y sin duración, despierta inmediatamente. 
La escena aparece con un tono renacentis$\mathrm{ta}^{12}$, se ve un prado, un locus amenos que crea un ambiente apacible y onírico. Pero la voluntad de ficción del Quijote y la estrategià del narrador y de Cervantes hacen despabilar los ojos al lector. Para saber si está despierto o dormido, Don Quijote se limpia los ojos; de inmediato, la diferencia entre lo real y lo soñado se pierde mágicamente en el texto: sueño y realidad se funden. Esta situación se parece suficientemente. a las meditaciones cartesianas:

Sin embargo, voy a considerar aquí que soy hombre y, por consiguiente, tengo costumbre de dormir y de representarme en sueños las mismas cosas o incluso menos verosímiles que esos insensatos cuando sueñan. ¿Cuántas veces me ha sucedido soñar por la noche que estaba en este lugar que estaba vestido, que me encontraba junto al fuego, aunque estuviese desnudo en mi lecho? En este momento me parece que no es con ojos dormidos como miro este papel, que esta cabeza que muevo no está dormida, que es con intención y con un propósito deliberado como extiendo esta mano y la siento: 10 que acontece en el sueño no parece tan claro y distinto como esto. Mas, pensándolo con detenimiento, me acuerdo de haber sido a menudo engañado durante el sueño por tạles ilusiones $y$, deteniéndome en este pensamiento, veo tan manifiestamente que no hay indicios ciertos por los que se pueda distinguir netamente la vigilia del sueño que me quedo sorprendido, y mi sorpresa es tal que es casi capaz de persuadirme de que estoy durmiendo (Descartes, 1987, 45).

Sin embargo, Descartes busca la salida a la confusión y encuentra la certeza racional en el estar despierto y razonando, mientras que Don Quijote encontrará la certeza en el sueño mis-

\footnotetext{
${ }^{12}$ La lectura de Peter N. Dunn-muestra que el pasaje y los acontecimientos del pasado, que incluyen el viaje de Ulises y Eneas quedan determinados, congelados en el pasado. Aquí en cambio interesa el proceso de actualización que el lector realiza y el efecto de simultaneidad de las épocas que se produce.
}

$\mathrm{mo}^{13}$. Como se ve, la elección de Cervantes desarregla el razonamiento cartesiano. En el texto no hay mediación: de un momento a otro se traspasa el umbral de lo real y todo sucede como un estar despierto en el sueño. En este momento el mundo moderno toma dos direcciones: el atajo de la razón, de la ciencia, del pensamiento y el de la imaginación, de la poesía, de la ficción. ¡Cuánto rato habrá que esperar para que de nuevo los dos caminos se junten, para que la filosofía y la poesía se encuentren! Sólo después de esta modernidad racional aparecen Menard y Borges, como un sobresalto histórico. Por eso, una lectura cuidadosa de esta aventura ayuda a comprender el problema. De ahí que, con este modo de leerla, se deconstruye el múndo cartesiano y se rompe la linealidad del tiempo: surge el Quijote de Menard que vuelve a la literatura tejido simultáneo:

Menard (acaso sin quererlo) ha enriquecido mediante una técnica nueva el arte detenido y rudimentario de la lectura: la técnica del anacronismo deliberado y de las atribuciones erróneas. Esa técnica de aplicación infinita nos insta a recorrer la Odisea como si fuera posterior a la Eneida y el libro Le jardin du Centaure de madame Henri Bachelier como si fuera de madame Henri Bachelier. Esa técnica puebla de aventura los libros más calmosos (Borges I, 450).

En este momento de la lectura, el lector habita con plenitud el mundo de lo imaginario, en un horizonte infinito en el que todos los personajes de la ficción simultáneamente se encuentran. De esta forma, todos los horizontes se juntan: el primer plano del lector ha abierto la puerta del libro; el segundo, del autor que ha inventado la ficción; el tercero, del personaje que está contando la historia; el cuarto, de los personajes que vuelven de la leyenda; el quinto, de Alonso Quijano; el siguiente, de Cervantes, y sigue. En fin, no hay manera de retornar porque

\footnotetext{
${ }^{13}$ Anthony J. Cascardi, en "Cervantes and Descartes on the Dream Argument", desarrolla estas relaciones desde esta aventura e incluye el capítulo 22 y el 24.
} 
a la vez, el primer plano es el último y todo se proyecta hacia el infinito. Como en un entrelazamiento de reflejos, el discurso ha conducido al lector a esta fusión de horizontes.

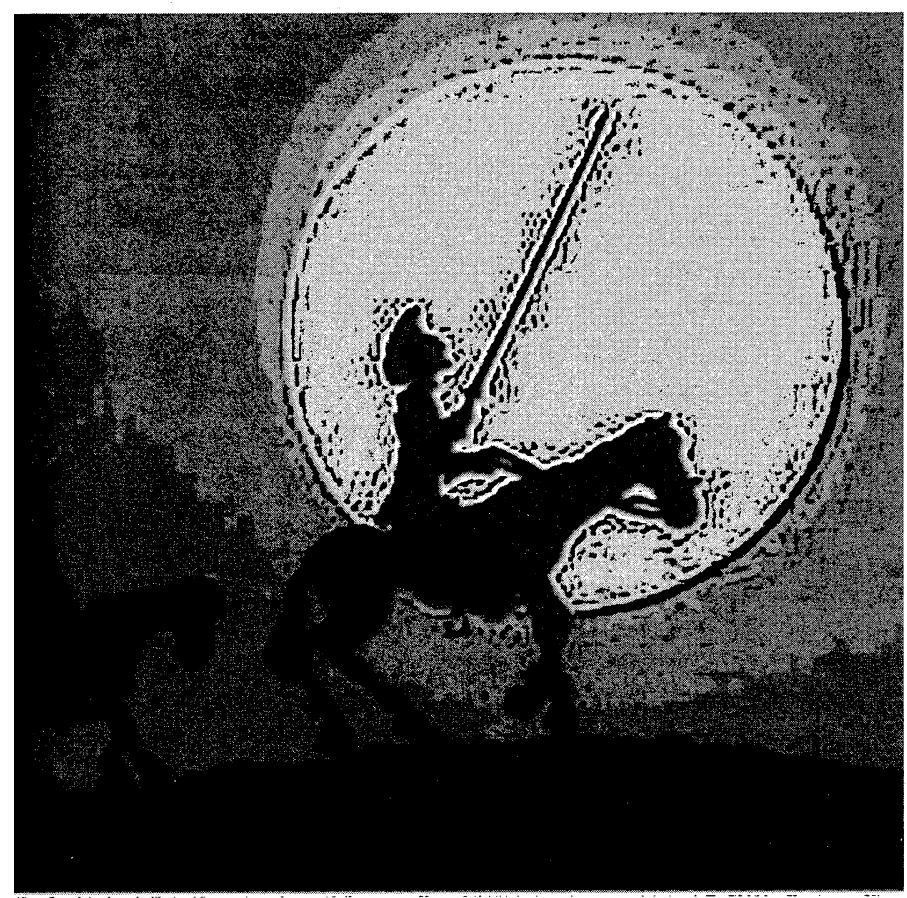

Ahora aparece un personaje en la cueva: inicialmente vemos su exterioridad, su vestidura. Se siente como el vestido es.la frontera de lo aparente, esa máscara visual que deja entrar y salir de los distintos planos de realidad. En este caso, el personaje, de quien no sabemos su nombre, viene cubierto con una capa. Al detalle se ve un contraste entre esta capa oscura y pesada y la transparencia del palacio. Esto produce una indiferenciación simultánea: el vestido oculta, el palacio desoculta o transparenta porque es de cristal, entonces, en la transparencia cristalina se ve el cuerpo pesado y en esa ocultación se ve la levedad espiritual.

Sólo ahora, el narrador, Don Quijote, caracteriza espiritualmente al personaje a partir de su imponente presencia física que revela su carácter interno. Inmediatamente, Don Quijote siente admiración y estremecimiento al abrazar a ese personaje fantasmal. Aquí se tocan y entretejen los dos mundos, que ya son ficticios de por sí; se diluye la separación entre el presente y el pasado, entre la leyenda y la novela. El lector se encuentra siempre entre los límites.
El acontecimiento se vuelve más complejo de lo esperado. Esa levedad luminosa que se colaba por una hendija pequeña se ha dispersado como un aire mágico. El lector experimenta el ericantamiento de un encantamiento; la iluminación despeja las sombras, pero sumerge todo en el misterio. En el aparente desencantamiento de Don Quijote surge el encantamiento de otro personaje, Montesinos:

Apenas me dijo que era Montesinos, cuando le pregunté si fue verdad lo que en el mundo de acá arriba se contaba, que él había sacado de la mitad del pecho, con una pequeña daga, el corazón de su grande amigo Durandarte y llevádole a la señora Belerma, como él se lo mandó al punto de su muerte (591).

El espacio adquiere un ambiente mágico; un halo fantasmagórico se despliega por todo el aire y el lector no alcanza a percibir la "realidad" del papel, la "realidad" del libro, la "realidad" de.Don Quijote: se halla abrazado por lo irreal. El libro rompe sus márgenes e irrealiza al lector y lo vuelve texto, ficción, encantamiento. Este efecto deconstructor no metafísico lo expone Jacques Derrida y es semejante a la propuesta borgiana. Estas características textuales muestran la proximidad de Cervantes con el pensamiento contemporáneo:

Pero -y en esto está el fondo del asunto-, toda exterioridad con relación al libro, toda esta negatividad del libro se produce en el libro. Se dice la salida fuera del libro, se dice lo otro y el umbral, en el librọ. Lo otro y el umbral no pueden otra cosa sino escribirse, reconocerse de nuevo en el libro. Sólo en el libro se sale del libro, puesto que para Jabès el libro no está en el mundo sino el mundo en el libro $(1989,103)$.

Se oye la voz que saluda a Don Quijote. ¿De dónde sale la voz? ¿Qué es la palabra, el lenguaje? ¿Acaso también proviene de la magia y por la costumbre lo hemos olvidado? Pero lo. particular de este instante de la narración es que hasta ahora sabemos quién es el extraño: es Montesinos.

Hay que observar que en el vestido, en la voz, en el nombre se hallan los rasgos de la eternidad. Montesinos es ese símbolo de lo imperecedero; la edad de la caballería retorna a escena. Bajo la apariencia se resguarda esa eternidad que 
ya no es platónica, sino que se hace historia en el instante, como lo expone Borges en "Historia de la Eternidad" (2001). Al ir hacia atrás, guiados por el texto narrativo, los lectores se tropiezan con esa permanencia que se esfuma en lo sensible. En este sentido, la lectura percibe esa eternidad que se desvanece en la simultaneidad del tiempo:

Ninguna de las varias eternidades que planearon los hombres -la del nominalismo, la de Ireneo, la de Platón- es una agregación mecánica del pasado, del presente y del porvenir. Es una cosa más. sencilla y más mágica. Es la simultaneidad de los tiempos (Borges I, 2001, 354).

Montesinos ha sido encantado, no sabemos hasta ahora por qué o por quién. El hecho es que ahí está. Se ha armado otra trama textual. El narrador, el Quijote en este momento, se siente tocado por la historia, por la leyenda y de inmediato reconstruye los hechos contados y le pregunta a Montesinos si fue él quien le sacó el corazón a Durandarte para llevárselo a su amada Belerma. Pero aclara que esa es la historia del mundo de arriba. Sin embargo, abajo también todo se hace lenguaje, narración dentro de la narración y los mismos personajes se vuelven escritura o rasgo gráfico; sólo que en el mundo de la ficción de abajo. De este modo, palabra y ser, nombre y personaje se confunden, como lo afirma Foucault:

Ahora bien, él mismo (Don Quijote) es a semejanza de los signos. Largo grafismo flaco como una letra, acaba de escapar directamente del bostezo de los libros. Todo su sèr no es otra cosa que lenguaje, texto, hojas impresas, historia ya transcrita. $(2001,53)$.

El Quijote quiere reconfirmar la historia; hay un detalle vago que luego se precisa, se trata del arma con que Montesinos le sacó el corazón a Durandarte: es un puñal y no una daga. Este elemento descriptivo acentúa el carácter de veracidad de la historia, a pesar de que es ficticia, para que el lector "no dude" en qué plano se encuentra.

Sancho por fin interviene. Como veremos, él parece ser un lazo de conexión con el mundo de arriba. Hace una aclaración sobre el puñal, pero para el Quijote no importa a quién pertenezca el arma. Esto muestra que hay una indiferenciación entre lo particular y lo general al caracterizar las cosas desde el plano de la ficción que es el universo del personaje. Es decir, es otra marca de ambigüedad que somete al lector a un estado intermedio, indefinido y complejo porque allí las cosas fluctúan como en la región de lo impreciso, de la duda, de lo incierto: se han vuelto ficción, discurso.

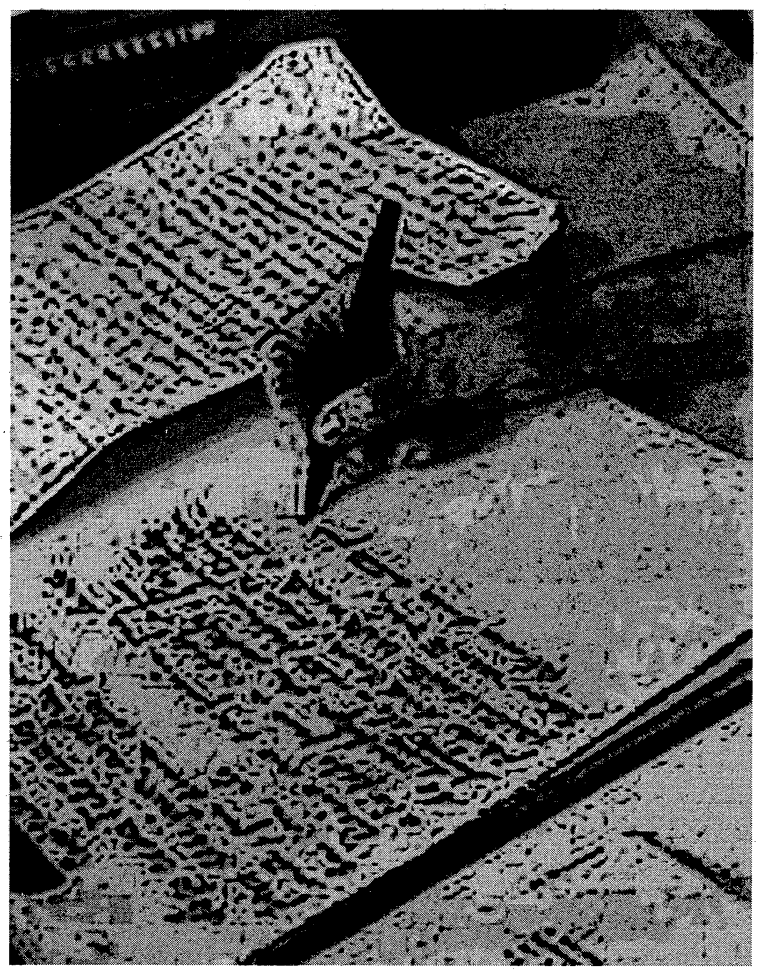

Don Quijote reitera que lo que importa es la verdad narrada y no la existencia de los hechos. Borges lo reafirma en Arte poética:

Ya no estoy -y espero que esto les parezca una herejía- demasiado seguro de las aventuras de Don Quijote. Désconfío de alguna de ellas. Creo que probablemente algunas son exageradas. Estoy casi seguro de que, cuando el caballero habla con el escudero, no urdía aquellos largos y estereotipados discursos. Sin embargo, esas cosas no importan; lo verdaderamente importante es el hecho de que yo creo en el propio don Quijote... Mientras que yo creo realmente en el propio caballero. Incluso 
si alguien me dijera que jamás han sucedido esas cosas, yo seguiría creyendo en don Quijote como creo en la personalidad de un amigo (2001a, 114).

Éste es el elemento estético de la literatura y particularmente del Quijote. Es decir, la imprecisión provoca que lo real se asuma como ficticio, pero, a la vez, como concreto, determinado y físicamente visible. Es decir, el personaje ficticio irrealiza todo y desdibuja los límites entre lo real y lo imaginario. El lector se deja.conducir por ese efecto, pero a su vez se distancia críticamente del texto porque al confundirse, comienza a pensar. El desconcierto lo conduce a la diferenciación simultánea.

Finalmente, interviene el primo y solicita a Don Quijote que continúe la historia. Aquí se entrecruza de nuevo el texto con la realidad. Este personaje estará presente, junto con Sancho, a modo de conciencia del mundo de arriba para Don Quijote; pero, conciencia desde la ficción, para que la configuración de la trama tenga verosimilitud. De esta forma, el libro se transforma en texto; esto significa que se rompe como unidad autónoma y se disemina para que el lector quede entrelazado en su tejido a la hora de leer. De cierta manera, el lector se vuelve personaje, se transparenta en el primo o en Sancho; a la vez que mira el mundo desde Don Quijote; entonces, consigue jugar con todas las tramas, se convierte en lector de lo múltiple y de lo simultáneo, es decir, en conciencia ficcionalizada.

Entre tanto, el primo invita a Don Quijote para que reanude la historia. El primo es el enlace textual entre las leyendas del pasado ${ }^{14}$, los acontecimientos de la aventura, todas las aventuras del texto de Cervantes y la historia en la que el lector se sitúa. Este mecanismo textual se repite varias veces en esta aventura como en toda la obra. Es una forma de entrelazar los episodios para que el lector no se pierda totalmente, sino que siga la secuencia narrativa y sienta los efectos del texto sobre él y lo reconozca como texto,

${ }^{14}$ Algunos críticos muestran las conexiones con la leyenda de Ulises y Eneas, pero indican que en la aventura se hacen referencias veladas a personajes que conocía Cervantes. como encadenamiento. Paul Ricouer sugiere que esos puntos de anclaje pueden ser aperturas del texto para que se potencie la historia desde la experiencia cotidiana del lector:

Sin abandonar la experiencia cotidiana, ¿no somos propensos a ver en tal encadenamiento de episodios de nuestra vida historias «no narradas (todavía)", historias que piden ser contadas, historias que ofrecen puntos de anclaje a la narración? No ignoro lo incongruente que es la expresión «historia no narrada (todavía)». La historia, ¿no es, por definición, algo narrado? Ciertamente si hablamos de historias efectivas. Pero ¿es inaceptable la noción de historia potencial? $(1987 \mathrm{a}, 148)$.

\section{Enigma y eternidad del encantamiento}

En esta sección de la narración suceden estos acontecimientos: Se refiera la leyenda, Montesinos está junto el sepuilcro de mármol, aparece Merlín y se cuenta cómo le sacó el corazón a Durandarte. Finalmente, se describen las señales que indican que está vivo:

No con menor lo cuento yo -respondió don Quijote-, y, así, digo que el venerable Montesinos me metió en el cristalino palacio, donde en una sala baja, fresquísima sobremodo y toda de alabastro, estaba un sepulcro de mármol con gran maestría fabricado, sobre el cual vi a un caballero tendido de largo a largo, no de bronce, ni de mármol, ni de jaspe hecho, como los suele haber en otros sepulcros, sino de pura carne y de puros huesos. Tenía la mano derecha (que a mi parecer es algo peluda y nervosa, señal de tener muchas fuerzas su dueño) puesta sobre el lado del corazón; y antes que preguntase nada a Montesinos; viéndome suspenso mirando al del sepulcro, me dijo: «Este es mi amigo Durandarte, flor y espejo de los caballeros enamorados y valientes de su tiempo. Tiénele aquí encantado, como me tiene a mí y a otros muchos y muchas, Merlín, aquel francés encantador que dicen que fue hijo del diablo; y lo que yo creo es que no fue hijo del diablo, sino que supo, como dicen, un punto más que el diablo. El cómo o 
para qué nos encantó nadie lo sabe, y ello dirá andando los tiempos, que no están muy lejos, según imagino: Lo que a mí me admira es que sé, tan cierto como ahora es de día, que $\mathrm{Du}^{-}$ randarte acabó los de su vida en mis brazos, y que después de muerto le saqué el corazón con mis propias manos; y en verdad que debía de pesar dos libras, porque, según los naturales, el que tiene mayor corazón es dotado de mayor valentía del que le tiene pequeño. Pues siendo esto así, y que realmente murió este caballero, ¿cómo ahora se queja y sospira de cuando en cuando como si estuviese vivo?» (592).

Este segundo mómento de la narración tiene que ver con las precisiones que se hacen sobre la historia. Desde un plano inferior, "en una sala baja", se construye la perspectiva de los acontecimientos. Hay una correspondencia perfecta entre el descenso y la muerte, que es como llegar al lugar de la eternidad misma ${ }^{15}$, pero encantada, poetizada. En un sepulcro de Mármol, más abajo, se encuentra Durandarte. La ficción se hace eternidad; el lenguaje y el texto han interconectado los tiempos. Hemos descendido al lugar de la muerte.

La fantasía revive los personajes: muerte y vida se conjugan. Con asombrosa precisión, el narrador, "Don Quijote", en una aclaración entre paréntesis, caracteriza la mano del personaje: es peluda y nervosa, es decir que desde su percepción le hace mirar al lector los rasgos físicos de la fuerza del héroe medieval. Este proceso de materializar lo espiritual y de espiritualizar la materia se va intensificando paulatinamente. En este instante, a través de esos detalles del caballero dormido en la eternidad, se van fusionando las dimensiones más opuestas: el cuerpo ya está muerto, pero se ha hecho espíritu. En su adormecimiento se conjugan, a través de estas apariencias, eternidad y materia.

Enseguida, la historia de Merlín es el nexo que teje la ficción. Él ha encantado a los personajes. Este elemento hace pensar, de nuevo, en las

\footnotetext{
15. En el artículo "The Literary Time in the Cueva de Montesinos, de Harry Sieber, se amplía esta problemática, pero no bajo la perspectiva del proceso de lectura o de la ruptura con el tiempo metafísico.
}

Meditaciones de Descartes porque de algún los textos se encuentran ${ }^{16}$ :

Yo supondría, pues, no que Dios - que es muy bueno y que es fuente soberana de verdad-, sino que cierto genio maléfico, no menos astuto y falaz qué poderoso, ha empleado toda su industria en engañarme; pensaría que el cielo, el aire, la tierra, los colores, las figuras, los sonidos y todas las demás cosas exteriores no son nada más que ilusiones y ensueños de que ha servido para tender trampas a mi credibilidad; consideraría que yo mismo carezco de manos, de ojos, de carne, de sangre, 'que no poseo ningún sentido, pero que creo falsamente tener todas esas cosas; permanecería obstinadamente ligado a ese pensamiento; y si con ese medio no está en mi poder el llegar al conocimiento de verdad alguna, al menos sí está en mi poder el suspender mi juicio. Por ello tendré buen cuidado de no dar crédito a ninguna falsedad y prepararé mi espíritu para todas las asechanzas de ese gran engañador tan bien que, por poderoso y astuto que sea, no podrá nunca imponerme nada. (Descartes, 1987, 49).

En Descartes, el genio maligno que hace ver los fantasmas es expulsado por el razonamiento; en Cervantes es recreado como el mago Merlín. De nuevo, la proximidad de los dos textos produce una duplicación en un espejo, sólo que esta contigüidad genera el distanciamiento de las dos

\footnotetext{
${ }^{16}$ Estas afirmaciones de Manuel Durán en su artículo "Perspectivismo en un capítulo del Quijote", aclaran estas relaciones con Descartes: "Para Descartes, los objetos son objetos de pensamiento, y con su hipótesis sobre la existencia de un "genio maligno" nos sume en graves dudas que no podemos resolver sin recurrir a Dios. A partir de este momento, el perspectivismo aparece una y otra vez en el pensamiento europeo y desempeña importante papel en Leibnitz y en Ortega.... El tipo de perspectivismo que encontramos en el Quijote nos produce una impresión distinta: un animado dịálogo, una serie de acciones y reacciones, ponen en contacto a los personajes guiados por distintas visiones de mundo, los obligan a evolucionar constantemente, a aceptar o rechazar los puntos de vista afines o contrarios, a habérselas con varios tipos de existencia, humana y figurada (la de los libros y los relatos leídos o comentados en el curso de la obra), y el lector, por su parte, tiene que hacer frente a tres tipos, por lo menos, de existencia..."
} 
vías de comprensión del mundo en la modernidad: la razón y la imaginación. La visión fantástica se queda en Don Quijote. Entonces, Cervantes insinúa a través de los comentarios del narrador que aquel mago está por encima de Dios y por encima del diablo. Así es como la perspectiva poética desborda la mirada racional y dicotómica.

De otro lado, no interesan las explicaciones de cómo y para qué el mago los encantó porque la historia se teje desde la dimensión poética del lenguaje. Por esta vía se logra multiplicar la mirada y hacer simultáneo el estar en el mundo. Esta manera de ver deja un margen inexplicado, precisamente, por esa disposición de orden estético que no es racional.

En este sentido, afirma Borges, la poesía es la expresión más concreta de las cosas: Montesinos cuenta que él mismo tomó el corazón, que pesaba como dos libras y afirma convencido que así fue. Este es un momento de intensidad poética porque todos los planos se tocan: lo espiritual y lo corporal (el corazón y el espíritu del encantado), lo permanente y lo fugaz (la eternidad imaginaria de la edad de la caballería que se disuelve en el sepulcro de mármol), lo particular y.lo universal (un caballero encantado que es como todos los caballeros encantados), la realidad y la imaginación (Don Quijote, Durandarte, Merlín y Montesinos en un texto fabulado), la literatura y la historia (la Edad Media, la edad moderna y la contemporaneidad del lector), en fin, el pasado, el presente y el futuro, la fabulación y la historia. Esta simultaneidad de horizontes acaba con la dicotomía de la caverna platónica: no hay que salir arriba de ella para contemplar las ideas y la eternidad; aquí mismo, abajo, entre sombras se da el contacto con lo ideal; más aún, en ese acontecimiento inmediato y fugitivo en que se lee el texto. Al estar en lo inmediato del entorno, aquí abajo, se experimenta una experiencia poética del mundo que, como dice Heidegger, es un morar entre la cercanía esencial de las cosas y la proximidad de los inmortales. Es lo que se experimenta en este momento del relato: una conjunción misteriosa entre la eternidad de lo lejano y la proximidad de los cuerpos que yacen ahí, detenidos en el tiempo:

Ésta (la existencia), en su fundamento, es «poética». La poesía, sin embargo, la en- tendemos ahora como el nombrar fundador de los dioses y de la esencia de las cosas. «Habitar poéticamente» significa: estar en la presencia de los dioses y ser tocado por la cercanía esencial de las cosas. Holderlin y la esencia de la poesía $(1983,62)$.

Ocurre un estallido desocultante en el que todas las esferas de lo divino, lo humano, los dioses y los seres humanos se tocan. Don Quijote y Durandarte, Dulcinea y Belerma, la luz y la oscuridad, se entrecruzan. En estas condiciones, la eternidad fluye como historia disuelta en el tiempo. No se puede determinar que una dimensión, el mundo de las ideas o eternidad, se imponga sobre la otra, el devenir, el mundo sensible. Todo subsiste en simultaneidad. El mundo inteligible se vuelve inconsistente, el alma de Durandarte queda en el mundo de lo corruptible, el corazón se deshace en la tierra y es sacado del cuerpo como obsequio para la amada. De este modo retorna a lo espiritual. Por tanto, cada vez que se lee la historia de Durandarte, se repite incesantemente la escena: el corazón se deslíe en el tiempo, pero también se vuelve ofrenda perdurable parà la amada; así, restituye su condición espiritual como símbolo del amor que no cesa nunca. Esto significa que todas las dimensiones de lo existente se tocan; ninguna se impone sobre otra; al contrario, se multiplican en sus diferencias. Lo que "es" está ahí, entre lo que se deshace; sin embargo, perdura cohesionado en lo diverso, sin cerramiento, sin fundamento. $\mathrm{Y}$ lo que existe se resguarda, escrito en un texto de ficción de ficciones que destruye y recrea el escenario para un nuevo lector. Este es el tejido de diferencias de una escritura diseminada entre lo sensible y lo inteligible, a la manera derridiana:

Si distinguimos el texto del libro, diremos que la destrucción del libro, tal como se anuncia actualmente en todos los dominios, descubre la superficie del texto. Esta violencia necesaria responde a una violencia que no fue menos necesaria. $(2003,25)$.

Por tanto, el libro de Cervantes se rasga como texto: conjunción simultánea de tiempos, espacios, épocas, lenguajes. Se hace superficie. 
textual que discurre por la palabra e hilvana el sentido diseminado. Provoca una apariencia de eternidad que se despliega por esa superficie textual con la que el lector también sè entrecruza. Se ve el corazón de Durandarte de nuevo inmortalmente putrefacto cada vez que se lee la aventura.

Esta intensidad poética se va cerrando en esta parte de la historia como una "sima" narrativa. Poco a poco el caballero encantado comienza a quejarse y a moverse. Ante el lector sucede la conjunción entre mortalidad e inmortalidad y el vínculo entre palabra y silencio. Así como la soga no se rompió cuando descendió don Quijote, que parece rememorar el desprendimiento del cordón umbilical, en este momento se anuda una cuerda invisible entre la muerte y la vida, entre el nacimiento y el fin, entre la eternidad y el cuerpo muerto. Se oye una canción.

\section{La canción del encantado}

\section{El corazón como si fuera el alma.}

La voz de Durandarte es una marca discursiva en verso que determina el tono de la queja. Para destacar este instante de confluencia expresiva, se ha dejado como una sección independiente. El poema reconcilia el mundo de la eternidad y el de la muerte:

Esto dicho, el mísero Durandarte, dando una gran voz, dijo:

¡Oh!, mi primo Montesinos

Lo postrero que os rogaba,

que cuando yo fuere muerto

y mi ánima arrancada,

que llevéis mi corazón

adonde Belerma estaba, sacándomele del pecho, ya con puñal, ya con daga (593).

La palabra sentimental irrumpe como canción que refleja el dolor del amor. Extrañamente, la canción dice que Montesinos es primo de $\mathrm{Du}$ randarte. He aquí otro contacto narrativo: Sancho y Don Quijote también están acompañados del primo. Hay una conexión velada, una familiaridad escondida entre estos dos personajes. Un primo no es ni hermano ni no hermano de alguien, crea un lazo intermedio. Esto muestra que las historias y los personajes se van duplicando. De otra parte, se vuelve a evidenciar en el poema la relación entre el alma y el corazón. Parece corresponder a una concepción platónica del ser humano, pero, más bien, se trata de una duplicación de realidades que no es una oposición excluyente. Al contrario, deja ver la simultaneidad de los dos ámbitos: el alma y el corazón perviven juntos en el encantamiento. Finalmente, el canto termina con una ambigüedad: para sacar el corazón usaron o una daga "o" un puñal. Sancho y Don Quijote ya han discutido esto, pero también queda sin resolver. De èste modo, a través de la interpretación de este canto se confirman las conexiones de las historias y de los géneros expresivos en este texto complejo.

\section{Encuentro de historias, aproximación de planos y personajes}

Comienza la quinta sección en la que las historias, los planos narrativos y los personajes se confunden. Éstos son los acontecimientos sobresalientes de esta parte de la narración:

Historia de cómo Montesinos llevó a Francia el corazón, cómo Merlín convirtió en lagunas a unas mujeres y cómo surgió la leyenda del rio Guadiana; de otro lado, se indica a Durandarte la presencia de don Quijote, aparece la procesión de doncellas, y con ellas llega Belerma, la amada de Durandarte; finalmente, Montesinos la compara con Dulcinea y Don Quijote se enfurece.

En esta quinta secuencia se reiteran los encuentros textuales. En este nodo del discurso se siguen configurando las relaciones entre historia e imaginación, entre eternidad y materia, entre poesía y naturaleza, entre eternidad y ficción. Del mismo modo, puede mostrarse cómo la obra de Cervàntes fluctúa entre la estética hegeliana y su desbordamiento en la estética contemporánea. Sobresale aquí el tratamiento del tiempo como hilo conductor, como soga que amarra los momentos que se deslizan por la historia.

Montesinos vuelve a relatar la historia de cómo llevó el corazón a Durandarte y la triste- 
za con que lo hizo. Lo histórico se repite en el relato, se ficcionaliza. El relato se configura en el devenir, a través de la repetición de sucesos que recrean la eternidad. Con el mismo procedimiento borgiano, como en el relato "Pierre $\mathrm{Me}$ nard, autor del Quijote", la escritura reconstruye el pasado en el texto narrativo con una exactitud poética mediante la ruptura del tiempo lineal.

A su vez, detalles como lavar el corazón con un pañuelo y echarle sal para que no se dañe. muestran que el prosaísmo del mundo, que Hegel nombra en sus Lecciones de Estética, se integra a lo ideal en la obra de arte, en la novela de Cervantes, como poético y repetible. Esos gestos cotidianos e insignificantes provenientes de la costumbre y la sabiduría popular se tornan esencialmente fugaces. El problema surge cuando este prosaísmo ha desbordado la obra poética y se establece la oposición entre lo prosaico y lo poético:

Este es el prosaísmo del mündo, según aparece la propia conciencia y la de los otros; un mundo de finitud y transformación, de mezcla en lo relativo y de opresión de la necesidad, al que el individuo no puede sustraerse. Por tanto, cada viviente aislado permanece en la contradicción de ser para sí mismo esta unidad cerrada, pero que a la vez depende de otros, mientras la lucha por la solución de la contradicción no va más allá del intento y la continuidad de la guerra permanente (Hegel, 1983, 98).

Pero ahora se hace una lectura distinta a la de Hegel. En una dialéctica que no idealiza, sino que duplica y multiplica las realidades, este prosaísmo del mundo no determina la muerte del arte, sino el surgimiento de la novela moderna. La escritura reconstruye la prosa del mundo. La obra de arte perdura debido al poder inmortalizante del encantamiento. Se lee esta historia inmersa en una región encantada que eternamente se deshace; con personajes fantasmales, pero de carne y hueso, irreales, pero corruptibles y condicionados por una realidad prosaica.

El carácter sentimental de esta obra de Cervantes es otro aspecto de la relación con la estética idealista. Hegel muestra que en la forma del arte romántico la interioridad determi- na la exterioridad: el río Guadiana es inmenso porque refleja la tristeza de Guadiana, el escudero de Durandarte. Y. toda la obra, por tanto, es una espiritualización del mundo desde la interioridad infinita de Cervantes que se desdobla en Don Quijote, en Sancho, en Montesinos, en Guadiana... Entonces, la naturaleza es reflejo del estado de ánimo de los personajes que supera las contradicciones del sujeto y las idealiza. Sin embargo, en la lectura contemporánea de la obra, esa sentimentalidad se fracciona en la exterioridad, se dispersa y se disemina; por tanto, no se concentra en la subjetividad ideal. Estos rasgos de la obra, vistos desde la estética idealista, prueban que la obra de Cervantes es un punto de ruptura entre la estética moderna y la contemporánea. A la vez, cierra una época y abre otra. Por ejemplo, desde la lectura de Don Quijote la siguiente afirmación de Hegel sobre el arte romántico queda relativizada, con ello el idealismo pierde su fundamentación:

El espiritu, que tiene como principio el acuerdo de sí consigo, la unidad de su concepto y de su realidad, puede hallar su existencia correspondiente sólo en su propio y nativo mundo espiritual del sentimiento, del ánimo, en suma, de la interioridad. Así llega el espíritu a la conciencia de tener su opuesto, es decir, su existencia, como espiritu para él y en él, :y sólo por ello gozar de su infinitud y libertad. (1985b, 20).

De algún modo, Don Quijote recoge todo el idealismo moderno y al mismo tiempo lo frac$\operatorname{tura}^{17}$ : Es decir, el hecho de que en Don Quijote

\footnotetext{
${ }^{17}$ La ambigüedad de Don Quijote corresponde a la ambigüedad de la estética de Hegel, pues ambos, bajo ciertos rasgos, se sitúan en el punto de quiebre entre lo moderno y lo posmetafísico. Por ello, estos comentarios de Hegel sobre el Quijote resultan inquietantes: "Don Quijote en su locura es un temple (anímico) por completo seguro de sí mismo y de su causa, o más bien sólo es esto: su locura, por la que permanece tan seguro de sí mismo y de su objetivo. Sin esta tranquilidad carente de reflexión respecto del contenido y la consecuencia de sus acciones, él no sería auténticamente romántico, y esta autocerteza, en relación con lo sustancial de sus disposición anímica es, en efecto, grande y genial, adornada mediante los más bellos rasgos de carácter" $(1985 \mathrm{~b}, 128)$.
} 
se exprese esa idealidad subjetiva del arte, provoca una lectura de la obra desde la estética contemporánea que es prioritariamente antihegeliana. Si se sigue esta caracterización, toda la naturaleza es un "espejo" de la interioridad humana porque hay una intimidad entre una y otra, entre lo interior y lo exterior. En ella el sujeto pierde su consistencia ideal. La geografía es un espacio espiritual e interior en el que se ve lo exterior: el río y las lagunas. Sumado a esto, los personajes son convertidos en ríos y la realidad se poetiza. Atrás resuena el río Acanto de Aquiles en la Iliada.

Pero éste ya no es el mundo mítico, por lo tanto, hay que leer la obra désde la teoría de la novela de Lukacs que no es idealista en ciertos sentidos. La recomposición del mundo no la hace el héroe mítico sino el carácter imaginante de Don Quijote, quien a través de la fantasía reconstruye la relación entre la naturaleza y lo humano. El héroe se vuelve abstracto frente al mundo y se lanza a la aventura, en este caso a la caverna; pero su decisión lo desacomoda, por eso su relación con el mundo exterior ser vuelve compleja y conflictiva. Sin embargo, antes que retraerse en un mundo ideal, Don Quijote recorre el paisaje sin dioses, afantasmado por el encantamiento de Merlín; entonces la relación entre la naturaleza y lo humano se transforma:

Que Dios ha abandonado el mundo, lo vemos en la inadecuación entre el alma y la obra, entre la interioridad y la aventura, en el hecho de que ningún esfuerzo humano se inserte ya en un orden trascendental. Esa inadecuación presenta, grosso modo, dos tipos: según que sea más estrecha o más amplia que el mundo exterior que le es asignado como teatro y como substrato de sus actos, el alma se estrecha o sè amplía. El idealismo abstracto. (Lukacs 1985, 363).

Esta relación se sigue precisando en la narración: la imagen hiperbólica que surge ahora muestra la intimidad entre la naturaleza y lo humano como algo fabulado, hecho leyenda pero sin la fuerza idealista del sujeto, porque en la narración se ha desvanecido. En el río, los peces son feos y desabridos por que sus aguas son producto de la tristeza de un hombre que llora lá- grimas saladas; por tanto, la historia no parece creíble sino una metáfora:

Guadiana, vuestro escudero, plañendo asimesmo vuestra desgracia, fue convertido en un río llamado de su mesmo nombre, el cual cuando llegó a la superficie de la tierra y vio el sol del otro cielo, fue tanto el pesar que sintió de ver que os dejaba, que se sumergió en las entrañas de la tierra; pero, como no es posible dejar de acudir a su natural corriente, de cuando en cuando sale y se muestra donde el sol y las gentes le vean (593).

La narración continúa y Montesinos anuncia la presencia de Don Quijote. De nuevo se tocan las historias en medio de la escritura de ficción. El discurso narrativo funde los tiempos.

Comienza un segundo momento de intensidad poética. Dos personajes novelados se encuentran. Eternidad y poesía pierden sus diferencias, confluyen mediante la escritura en un tejido en simultaneidad. No se sabe, como dice, Borges, quién fue primero y quién después, si Don Quijote o Durandarte. El hecho tiene alcances insospechados; incluso el lector se queda absorto ante la escena porque acuden todas las épocas de la historia a su horizonte mundano. El hecho es que los tres (Don Quijote, Durandarte y el lector) están frente a frente. Idénticos, los textos salen a la luz como históricos y en este encuentro se reacomoda el lector. La obra vuelve a escribirse exactamente igual, la historia se repite como en un espejo, la verdad y el tiempo se hacen discontinuos:

Es una revelación cotejar el Don Quijote de Menard con el de Cervantes. Éste, por ejemplo, escribió (Don Quijote, primera parte, noveno capítulo):

... la verdad, cuya madre es la historia, émula del tiempo, depósito de las acciones, testigo de lo pasado, ejemplo y aviso de lo presente, advertencia de lo por venir.

Redactada en el siglo XVII, redactada por el «ingenio lego» Cervantes, esa enumeración es un mero elogio retórico de la historia. Menard, en cambio, escribe: 
...la verdad, cuya madre es la historia, émula del tiempo, depósito de las acciones, testigo de lo pasado, ejemplo y aviso de lo presente, advertencia de lo por venir.

La historia, "madre» de la verdad; la idea es asombrosa. Menard, contemporáneo de William James, no define la historia como una indagación de la realidad sino como su origen. La verdad histórica, para él, no es lo que sucedió; es lo que juzgamos que sucedió. Las . cláusulas finales -ejemplo y aviso de lo presente, advertencia de lo por venir- son descaradamente pragmáticas (Borges 2001, 449).

De nuevo se oye la voz de Durandarte, el encantado, el muerto, el vivo. Habla a media voz, debido a su ubicuidad temporal inmortal:

«Y cuando así no sèa-respondió el lastimado Durandarte con voz desmayada y baja-, cuando así no sea, joh primo!, digo, paciencia y barajar » (594)*.

Se calla. Retorna al silencio de la muerte, donde se resguardan las palabras. El silencio se rompe con los alaridos y los cantos de las doncellas que se lamentan en procesión. Vienen vestidas de negro en medio de la transparencia del castillo. Se produce un contraste de luminosidad que parece un claroscuro entre la muerte y la vida.

Sobresale un personaje femenino. No se sabe quién es. Su vestido es blanco y negro, trae en sus manos un corazón momificado. La descripción física es muy precisa:

Su turbante era mayor dos veces que el mayor de alguna de las otras; era.cejijunta, y la nariz algo chata; la boca grande, pero colorados los labios; los dientes, que tal vez los descubría, mostraban ser ralos y no bien puestos, aunque eran blancos como unas peladas almendras; traía en las manos un lienzo delgado, y entre él, a lo que pude divisar, un corazón de carne momia, según venía seco y amojamado (594).

La mujer es Belerma y tiene un àspecto feo. Las mujeres están llorando al caballero muerto en un ritual eterno. Esta escena es una repetición circular $^{18}$. Un tiempo que vuelve cada vez que se va, un lamento que se oye cada vez que se calla, una escena que retorna cada vez que se lee. Es como el rito de la lectura y la escritura. $\mathrm{Al}$ abrir el texto, en cada ocasión, la escena surge de nuevo y queda escrita en la experiencia del lector.

La fealdad de Belerma se debe al dolor por su amante. Sin embargo, Montesinos la compara con Dulcinea. Este elemento también entrelaza las historias: un personaje, Montesinos, establece el paralelo para que los textos se junten. Dulcinea tiene una fealdad externa a la idealización de Don Quijote, es una labradora que no aparece tal. La historia del Belerma es igual, pero en sentido inverso, ha idealizado a su héroe. De ahí que las historias de Don Quijote y Durandarte tengan semejanzas y diferencias. Pero en Don Quijote se destruyen los principios ideales con un tono irónico que se irriga por todo el texto, por eso la situación es contraria en la historia de Montesinos. Sin embargo, al ser novelada por Don Quijote, se actualiza y adquiere nuevas connotaciones. Es una idealización multiplicada en la ficción, pero sin principios fundamentales ni verdaderos que las sostengan, por tanto, se narra como una no idealización.

Dulcinea es incomparable. Don Quijote reitera la diferencia. Este efecto es poético porque logra evidenciar en la diversidad, en la diferencia, el encuentro. Éstas son dos historias que eternamente se encuentran, pero sus personajes son diferentes y a la vez semejantes. ¿Acaso esa no es la relación más auténtica entre la caballería ideal y la novela moderna que se volverá novela pośmoderna?

Mediante una adulación enmascarada, Montesinos se disculpa y exagera al comparar a Dulcinea sólo con el cielo. De esta forma, la tensión entre Don Quijote y Montesinos, debido a esta comparación, termina. Así finaliza esta sección del relato.

\footnotetext{
is Borges, Heidegger y Ricouer han hablado de esta circularidad temporal. Más que una repetición circular cerrada, se trata de un movimiento circular en espiral que se prolonga sin fin y se guarda en la memoria. E1 texto narrativo, al momento de ser leído, recrea esta temporalidad. Por eso es posible la cercanía entre el tiempo del relato y el tiempo del lector.
} 
Entre la realidad y la ficción, entre la mentira y la verdad, entre lo actual y lo pasado

La sexta secuencia narrativa se desarrolla de la siguiente manera:

Don Quijote evitó luchar con Montesinos por la comparación que hizo con Dulcinea; más de una hora ha pasado pero el tiempo para Don Quijote se hace relativo; el primo pregunta si los encantados comen, si duermen; Sancho dice que no cree la historia y que Merlín le encantó el cerebro al Quijote; Don Quijote replica que lo que cuenta es cierto, lo vio y lo tocó.

Esta nueva sección comienza con un retorno al plano general de la obra en el que se encuentran Sancho y Don Quijote. La historia de Durandarte queda como horizonte de fondo. Interviene Sancho y se asombra de que Don Quijote no le haya pegado a Montesinos por la comparación. De nuevo, se enlaza la leyenda de Durandarte con la historia de Don Quijote, esto produce una recomposición de los planos narrativos. Los diálogos entre Don Quijote, Sancho y el primo anudan el discurso.

La convicción de Don Quijote sobrepasa cualquier malestar menor, como el de la comparación que hace Montesinos entre Belerma y Dulcinea. Esta actitud deja ver una relación entre lo estético y lo ético porque Don Quijote mantiene una coherencia entre su actitud y su creencia en que lo imaginario es el sustento del mundo real. Es decir, cree que lo novelado configura un universo autónomo que relativiza los detalles y en consecuencia las acciones humanas.

En este juego ficticio entre los planos narrativos, el primo, su otro oyente, pregunta por el tiempo. Sancho reitera este juego imaginario: "-Verdad debe de decir mi señor -dijo Sancho-, que, como todas las cosas que le han sucedido son por encantamento, quizá lo que a nosotros nos parece una hora, debe de parecer allá tres días con sus noches" (596).
De hecho, la temporalidad de la ficción cohesiona los diferentes tiempos en esta aventura y produce un efecto de simultaneidad en el que no se distingue el tiempo del encantamiento del tiempo real. Estas dimensiones temporales se intercambian y se dispersan en muchas direcciones y niveles y afectan todo el texto cervantino. Duración y medición del tiempo (Sieber, 1971) se funden una en otra. Por esto, el primo traspasa estos planos para lograr que el lector desde su propia temporalidad entre en contacto con la temporalidad ficticia de Don Quijote, con la temporalidad del encantamiento de Merlín y con la temporalidad construida por el autor. Para Don Quijote han pasado tres días, mientras que para ellos, sólo más de una hora. Surge, entretanto, la pregunta sobre cómo se funden los planos temporales y qué sucede con la temporalidad del lector.

Para desplegar esta confluencia temporal el mecanismo textual es el diálogo. Por tanto, el diálogo que se encuentra en el relato en los diversos instantes de la aventura es un llamado al diálogo oculto que sucede entre el texto y el lector, como lo afirma Ricoeur:

En efecto, la relación escribir-leer no es un caso particular de la relación hablar-respònder. No es ni una relación de interlocución ni un caso de diálogo. No basta con decir que la lectura es un diálogo con el autor a través de su obra; hay que decir que la relación del lector con el libro es de índole totalmente distinta. $\mathrm{El}$ diálogo es un intercambio de preguntas y respuestas, no hay intercambio de este tipo entre el escritor y el lector; el escritor no responde al lector; el libro separa más bien en dos vertientes el acto de escribir y el acto de leer que no comunican; el lector está ausente en la escritura y el escritor está ausente en la lectura. El texto produce así un doble ocultamiento: del lector y del escritor, y de esta manera sustituye la relación de diálogo que une inmediatamente la voz de uno con el oído del otro. $(1999,61)$.

Ésta es la relación entre tiempo y narración de Ricouer: el tiempo se disuelve en el relato que es la configuración mimética de la disolución temporal del lector, quien en la tercera mi- 
mesis, al tomar distancia del texto, la reconoce como su temporalidad propia. El lector se despliega en el tiempo de la lectura en un juego dialógico con el texto que lo interpela y lo encadena el tiempo de la narración. El diálogo es la marca textual de esta reciprocidad. Así se va tejiendo el texto y el entretexto con el lector. Por esto, es significativo atender a estos diálogos que aparecen en la aventura.

El encantamiento produce esta temporalidad. Lo que llama la atención es el modo como se da el encuentro entre lo encantado y lo desencantado. La secuencia narrativa inadvertidamente ha inventado ese tiempo en el que el lector se disuelve. Sancho y el primo representan el enlace con el tiempo del desencantamiento; de ahí que cuando intervienen en la narración, pregunten a Don Quijote por esos detalles que rompen. el encantamiento, pero también ellos se encuentran dentro del tejido de lo fabulado ${ }^{19}$, que en otro nivel es un encantamiento, el provocado por el autor.

Sin embargo, Don Quijote hace caso omiso del llamado de atención de estos personajes y olvida la diferencia entre lo que es ficción y lo que es realidad. De manera que la ficción se sobrepone a los dos planos del tiempo: la duración que es más de carácter relativo y subjetivo y la medición que tiene un carácter objetivo y universal se confunden en el relato.

Seguidamente, viene un diálogo con el primo sobre la comida. Del mismo modo, los procesos biológicos son accidentales frente a una temporalidad esencial imaginaria. Sancho y el primo hacen preguntas sobre el comer. La intención ahora es comprender cómo se da la relación entre un cuerpo encantado y otro que parece no encantado, pero que es producto de otro encantamiento, la obra de Cervantes. Contradictoriamente, el efecto del encantamiento para Don Quijote se manifiesta fisiológicamente en la posibilidad de no comer. Así como ellos, Duran-

\footnotetext{
19 Ricouer en "La construcción de la trama" establece una relación complementaria entre mimesis y mythos, es decir, entre imitación y fabulación, desde la poética de Aristóteles. Esto ayuda a comprender la relación con el texto de Cervantes (1987a). Significa que lo mimético se vuelve fábula, apariencia-de verdad narrada.
}

darte, Belerma o Montesinos, Don Quijote no come, no existe como materia. Estos rasgos de la narración revelan el proceso de inmaterialización que se ha mencionado antes.

La sutil diferencia entre estos personajes se ha borrado, la fantasía los ha transformado bajo una sutil precisión orgánica y su cuerpo puede pasar de una región a otra sin sufrir alguna mutación. El cuerpo se vuelve ficción y su fisiología también. En un estado irresoluble, su materia biológica queda suspendida como un espíritu y actúa como tal. Sin embargo, Don Quijote es consciente de sus diferencias con esos personajes cuando reconoce que a. los muertos les crecen las uñas y el cabello. $\mathrm{A} 1$ darse cuenta de ello, la conciencia de que al morir ocurre este fenómeno biológico desborda el encantamiento, entonces, el lector y el mismo Don Quijote quedan sin saber si estos cuerpos son cadáveres, invenciones o seres humanos vivos.

Aquí se llega al punto nodal de la historia: la relación entre la ficción y la realidad que se multiplica en infinitos planos. Sancho es quien pregunta si los encantados duermen. Su amo responde que no. $Y$ se desata la discusión sobre el estar despierto y el estar dormido. De nuevo, las diferencias desaparecen y el proceso de ficcionalización se acentúa, en consecuencia, la ambigüedad también.

Don Quijote reflexiona sobre el asunto. En este momento, la cuestión anticartesiana se vuelve más evidente. Lo imaginario se despliega sobre todos los niveles de existencia: sobre la cosa pensante y sobre la cosa extensa. Piensa cómo él ya se parece a ellos, porque ni ha comido ni ha dormido.

De inmediato, en este contrapunto entre Don Quijote y Sancho, viene el cuestionamiento de su escudero. "Pero perdóneme vuestra merced, señor mío, si le digo que de todo cuanto aquí ha dicho, lléveme Dios, que iba a decir el diablo, si le creo cosa alguna" (596). Su escepticismo prueba que la verdad es ambigua. ¿Cómo puede cuestionar un personaje ficticio a otro que está suspendido en la ficción del encantamiento? ¿Quién es más verdadero de ellos? ¿Quién dice la verdad, quien miente? ¿Cuál historia es la verídica, cuál es la imaginaria: la novela de Cervantes, la historia de Don Quijote, la aventura de Montesinos, la leyenda de Durandarte, en fin? 
Y el primo no contradice a Don Quijote, lo que genera aún más duda. De nuevo, el lector se encuentra en medio de una ambigüedad más ambigua, es decir, en el ámbito de la poesía, como lo dice Heidegger en De camino al Habla: La poesía habla desde una ambigüedad ambigua (69).

$\mathrm{Ni}$ los personajes ni el lector tienen certeza de su ubicación; sin embargo, en ellos confluyen todos los nexos entre irrealidad y realidad. La hendija inicial que dejaba pasar una tenue luz, ahora se ha dispersado por todos los objetos, los personajes, las acciones y el lector. Pero esta imprecisión los determina aún más. Además, Sancho afirma que efectivamente su amo ha dicho la verdad. El lector ya no sabe a quién creerle. Queda en suspenso. Y Don Quijote replica e insiste que eso es verídico. De este modo, se ha constituido el mundo, bajo el principio de la ambigüedad y la simultaneidad.

Sancho sigue con dudas y hace un razonamiento semejante al cartesiano, sólo que la conclusión es inversa. Merlín es como el genio maligno de Descartes que le ha puesto una especie de máquina en el cerebro a Don Quijote para que vea lo que ve. Puras ensoñaciones, puras ficciones: "-Creo -respondió Sancho- que aquel Merlín, o aquellos encantadores que encantaron a toda la chusma que vuestra merced dice que ha visto y comunicado allá bajo, le encajaron en el magín o la memoria toda esa máquina que nos ha contado, y todo aquello que por contar le queda" (596). Pero, en Descartes la razón da muerte al genio mientras que para Sancho, Merlín continúa provocando el reencantamiento del mundo.

Sin embargo, Don Quijote reitera que todo lo que cuenta es verdad. El genio de la escritura, por tanto, en este caso, es el Merlín que vuelve todo ficción, siendo él mismo ficción. En consecuencia, Cervantes es el genio maléfico que transformó todos los planos de realidad en fabulación. Resurge la relación con Borges. Todo lo que sucede es sueño de sueño, ficción de ficción. De modo que detrás de Descartes está el soñador que a su vez es un sueño. Éste es el punto más bajo de la caverna en la historia de Cervantes, pero a su vez, el más alto. Esta ficción de ficción que produce una ambigüedad irresoluble sobrepasa lo metafísico y se proyecta ha- cia lo posmetafísico, a través del texto borgiano. En Pierre Menard se repite exactamente lo mismo: se inventa a Menard como el otro autor del Quijote que es el mismo y otro simultáneamente. Como se ha visto, el encantamiento resguarda la eternidad, entretanto, la escritura abre la caverna encantada para que el texto se vea fluyendo transparente en un palacio de cristal a la espera de un lector. Entonces, al leer el "texto" todo se escribe exactamente igual, es decir, se crea. En este punto de la historia se tejen todos los ámbitos de lo sensible y lo inteligible; sin diferenciación, pero bajo el rigor de las diferencias. Surge, según Gadamer, el texto poético en èl-que:

La palabra del poeta participa también de una ambigüedad semejante. También para ella es cierto que es mítica, es decir, que no puede refrendarse por algo exterior a ella. La multivocidad de la palabra poética tiene su auténtica dignidad en que corresponde plenamente a la multivocidad del ser humano. Todo interpretar de la palabra poética interpreta sólo lo que la poesía misma ya interpreta. Lo que la poesía interpreta y lo que ella señala no es, naturalmente, lo que el poeta mienta $(1996,79)$.

\section{Las labradoras}

Ésta es la séptima secuencia narrativa que se ha propuesto y esta conformada por los siguientes acontecimientos secundarios:

Don Quijote cuenta cómo Montesinos le mostró tres labradoras y entre ellas reconocieron a Dulcinea, Sancho ser rie y le pregunta cómo reconoció a su ama.

-Todo eso pudiera ser, Sancho -replicó don Quijote-, pero no es así, porque lo que he contado lo vi por mis propios ojos y lo toqué con mis mismas manos. Pero, ¿qué dirás cuando te diga yo ahora cómo, entre otras infinitas cosas y maravillas que me mostró Montesinos, las cuales despacio y a sus tiempos te las iré contando en el discurso de nuestro viaje, por no ser todas deste lugar, me mostró tres labradoras que por aquellos amenísimos campos iban saltando y brincando como cabras; $\mathrm{y}$, apenas las hube visto, cuando conocí ser la 
una la sin par Dulcinea del Toboso, y las otras dos aquellas mismas labradoras que venían con ella, que hablamos a la salida del Toboso? Pregunté a Montesinos si las conocía, respondióme que no, pero que él imaginaba que debían de ser algunas señoras principales encantadas, que pocos días había que en aquellos prados habían parecido; y que no me maravillase desto, porque allí estaban otras muchas señoras de los pasados y presentes siglos, encantadas en diferentes y estrañas figuras, entre lạs cuales conocía él a la reina Ginebra y su dueña Quintañona, escanciando el vino a Lanzarote, cuando de Bretaña vino (596).

En esta sección del relato hay un retorno a la historia dentro de la historia, después de ese momento metapoético del diálogo anterior. E1 lector misteriosamente vuelve al lugar del encantamiento, ahí se multiplican los planos de ficción y, a su vez, se entrelazan con mayor precisión. La sección inicia con un momento de conciencia por parte del narrador, Don Quijote, quien expresa que lo que está haciendo es contar, pero que lo que le sorprende es que ve frente a sí tres labradoras y una de ellas es Dulcinea; esto le desdibuja los límites. Es decir, se ha perdido.en medio de la ficción de la ficción, como nosotros, los lectores.

Don Quijote le pregunta a Montesinos si la conoce porque es muy famosa por la historia que se cuenta de ella. Dulcinea en la dimensión del encantamiento pierde la diferencia temporal. La historia se hace simultánea, muchos personajes del mundo de Montesinos están junto a ella, según lo presupone él. El mundo de la eternidad se disuelve en la magia del encantamiento que ya no tiene fronteras. Como siempre, la conciencia ficticia de Sancho le permite deducir que lo que ha pasado es que su amo ha perdido el juicio. Él sabe que Dulcinea fue producto del encantamiento. Ésta es una especie de desenmascaramiento de la historia; con poco éxito para el lector y para los personajes, claro está.

Y le inquieta que por determinación del destino su amo haya tenido que bajar hasta esta caverna, para desquiciarse más. De este modo; van convergiendo muchas relaciones. $\mathrm{El}$ sueño, la locura y la muerte se han entrelazado en esta ca- verna, pero ninguna se impone sobre la otra. $\mathrm{La}$ experiencia es mucho más difícil porque se perciben todos los planos de la fićción en un mismo instante. ¡Ah del lector si no tiene un oído multiplicado y una imaginación rota! Por fortuna, Sancho nos ha ayudado a construir una perspectiva que fusiona estas relaciones; pero este efecto textual vuelve más abismal y estremecedor el proceso de lectura de la novela de Cervantes y de todo texto de ficción.

Extrañamente el comentario de Sancho aumenta la incertidumbre. La historia nos ha hecho descender, Sancho dice que su amo está mejor "acá arriba", cuando la historia de Don Quijote nos tiene acá abajo. Esste contrapunto produce mayor imprecisión, es como un juego entre la locura de estar abajo y la sensatez de estar arriba; sin embargo, a medida que se lee la historia todo se desubica. Esto significa que la dialéctica entre el bajar y el subir se ve realizado desde la ficción. La caverna platónica gira doblemente y no puede sostenerse ni en el mundo sensible ni en el inteligible, ni arriba ni abajo. Con ironía, Don Quijote, fantasma pleno, hace caso omiso de las reflexiones de su escudero.

Sancho sigue cavilando: descree de las palabras de su amo. El lector se encuentra entre dos mentiras, entre dos lenguajes: el de Sancho y el de Don Quijote. Foucault, en cierta forma, al pensar en Don Quijote, se da cuenta de que la relación entre la palabra y la cosa se ha transformado. La palabra no se refiere a una cosa y la cosa no es un objeto al que se le asigna una palabra. Si se nombra algo, la cosa aparece ahí. Es decir, el lenguaje poético restablece la palabra para que no sea sólo instrumento. De manera que el lector no puede creer ni en la palabra de uno ni de otro, pero experimenta el mundo como lenguaje, como semejanza, como mundo:

Y cada episodio, cada decisión, cada hazaña serán signos de que Don Quijote es, en efecto, semejante a todos esos signos que ha calcado.

Pero si quiere ser semejante a ellos, tiene que probarlos, porque los signos (legibles) no se asemejan ya a los seres (visibles). Todos estos textos escritos, todas estas novelas extravagantes carecen justamente de igual: nada en el mundo se les ha asemejado jamás: su lenguaje 
infinito queda en suspenso, sin que ninguna similitud venga nunca a llenarlo; podrían arder por completo, la figura del mundo no:cambiaría: $\mathrm{Al}$ asemejarse a los textos de los cuales es testigo, representante, análogo verdadero, Don Quijote debe proporcionar la demostración y ofrecer la marca indudable de que dicen verdad, de que son el lenguaje del mundo (Foucault, 2001, 53).

Estê momento de tensión entre èl amo y su escudero termina; Sancho le pregunta si Dulcinea le ha dicho algo. $Y$ como ha sucedido repetidamente, este diálogo es otra forma de hilar los planos de la ficción, para que la palabra sea esencial. De nuevo, el lector queda ligado al texto de un modo estético muy particular:

La percepción estética así entendida solo puede surgir de una desconceptualización del mundo, con el fin de hacernos divisar las cosas en la manifestación liberada de su pura visibilidad $(2002,65)$.

\section{Dulcinea encantada}

Don Quijote reconoce a Dulcinea por los vestidos, quiso seguirla y bablarle pero ella buye. Ella le manda pedir prestados 6 reales, Don Quijote dice que no tiene y quiere desencantarla para retenerla: le manda cuatro con la doncella para Dulcinea y la doncella brinca y se va.

Finalmente, la historia se centra en las referencias a Dulcinea. Don Quijote la reconoce por el vestido. La relación entre la apariencia y la existencia es ambigua. Lo que aparece es el ser de quien esta ahí: el vestido oculta el espíritu. Como en una evocación de Dante, al llamarla, ella lo ignora y huye.

Para entrelazar simultáneamente aún más los planos de la historia, Don Quijote dice que Montesinos le advirtió que ya no la siguiera porque debía subir y salir de la caverna, esfumarse del encantamiento. Esto indica que los personajes traspasan los planos ficcionales; tienen como una clarividencia cristalina, como si el castillo transparente les dejara ver el futuro. Así las fron- teras entre lo real y lo fantástico se rompen. Enseguida, Montesinos.le dice que habrá un tiempo para desencantar a los personajes.

Àlguien aparece súbitamente, le trae un recado de Dulcinea pero le produce pena a Don Quijote porque le manda pedir dinero con una doncella. Dulcinea queda en un segundo plano y en el fondo de la historia, casi inexistente. Con actitud ingenua Don Quijote pregunta a Montesinos si los encantados tienen necesidades. Irónicamente, Montesinos le insinúa que le envíe el dinero para sus necesidades. Esta caracterización de tipo prosaico muestra que no se trata de personajes ideales; sino de seres de carne y hueso que dependen de relaciones inmediatas y están determinados por las circunstancias.

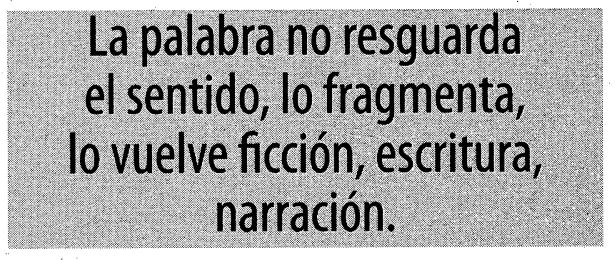

Mediante una acotación dirigida a Sancho, Don Quijote reacciona molesto porque sólo puede darle 4 reales. Este rasgo anímico indica que el personaje sufre un hondo conflicto: se halla en el borde de los mundos y se debate entre el ser conciente de sus actos y el enamoramiento. $\mathrm{El}$ texto deja ver la tensión interior de un personaje complejo que lucha con el mundo real y con el mundo imaginario. Don Quijote reconoce además que su propósito es desencantar a Dulcinea y que sólo eso le hará retornar a sí mismo y producir tranquilidad, porque en este momento ella le ha producido dolor. Quizá alcanza a comprender que ella es una proyección de su imaginación. La soga de la cueva se tensa tanto entre los dos mundos que parece romperse.

La doncella recibe el mensaje del Quijote sin entender la situación. Da un brinco y se va. Esta actitud acrecienta el dolor del Quijote. La doncella surge dentro del mundo encantado por Merlín, pero más bien parece que proviene de un mundo desencantado y prosaico que Don Quijote no reconoce. Este es un juego de espejismos en el que los seres humanos se hunden. Sin embargo, este juego produce en el personaje una toma distancia que le hacer comprender su propia situación con- 
tradictoria. Don Quijote alcanza cierto grado de conciencia a través de estos rasgos prosaicos. Este tono irónico también es un llamado al lector para que tome distancia y haga una lectura crítica del texto. Jauss lo explica de este modo:

Estos procedimientos pueden agruparse bajo el nombre de identificación irónica: el espectador o el lector que se resiste a la esperada identificación con lo representado es rescatado de la inmediatez de su comportamiento estético, con el fin de posibilitar la reflexión de la conciencia receptora y liberarla para actuar personalmente. $(2002,84)$.

\section{Entre la locura y el sentido}

\section{Sancho se pregunta qué le ha hecho perder el juicio al Quijote.}

La aventura se cierra con la preocupación de Sancho porque parece que su amo ha entrado en la locura. Como en un efecto de salida y entrada en el mundo del encantamiento que produce un movimiento pendular, el lector también lucha entre la locura y la razón, entre el estar fuera y dentro del texto simultáneamente: entre esta aventura y todo el texto cervantino, entre el texto del Quijote y todos los textos.

Hay una súplica a Dios para que regrese el sentido a su amo. Pero se sabe que será inútil. El efecto desquiciante de la literatura es inevitable.

\section{Retorno al plano de la narración primaria}

- Oh santo Dios! dijo a este tiempo dando una gran voz Sancho-- ¿Es posible que tal hay en el mundo, y que tengan en él tanta fuerza los encantadores y encantamentos, que hayan trocado el buen juicio de mi señor en una tan disparatada locura? ¡Oh señor, señor, por quien Dios es, que vuestra merced mire por sí y vuelva por su honra, y no dé crédito a esas vaciedades que le tienen menguado y descabalado el sentido!

-Como me quieres bien, Sancho, hablas desa manera -dijo don Quijote-; y, como no estás experimentado en las cosas del mundo, todas las cosas que tienen algo de dificultad te parecen imposibles; pero andará el tiempo, como otra vez he dicho, y yo te contaré algunas de las que allá abajo he visto, que te harán creer las que aquí he contado, cuya verdad ni admite réplica ni disputa (599).

Se cierra el relato con la respuesta del Quijote frente a la preocupación de su escudero. $\mathrm{El}$ lector queda en manos de su soñador, inalterado, decidido a mantener abierta la puerta de la cueva de Montesinos, a prefigurar en el futuro, en otra lectura del texto, una historia más imaginaria, por tanto, más creíble y más verdadera.

Éste ha sido el paso por el texto. Ha sido el recorrido por el tejido de la ambigüedad, que va anudando lo fantástico y lo real y al mismo tiempo va produciendo un efecto de simultaneidad: entre la mirada de Sancho y el primo, en mitad de los cristales del palacio de Montesinos y Durandarte, entre las fronteras entre la vida y la muerte, por entre la fisura del tiempo, bajo el movimiento circular en la eternidad del encantamiento en el que los cuerpos se deshacen en la perdurabilidad de lo fugitivo. Sin dioses, sin mundo inteligible que sustente el mundo de la apariencia se ha construido la caverna de la destrucción imaginaria del lenguaje que se quiebra en infinitos instantes. La palabra no resguarda el sentido, lo fragmenta, lo vuelve ficción, escritura, narración. El libro de la metafísica de los fundamentos se ha destruido. Se ha dado el juego múltiple de deconstrucción entre el mundo del texto y el mundo del lector.

Esta experiencia de lectura ha mostrado que el lenguaje, lejos de ser un sistema autónomo que explica los acontecimientos del habla, es el habla misma y por ende escritura y silencio para la escucha. Sólo como escritura que se lee, como diálogo entre lector y texto, el lenguaje sucede. Éste es su carácter discursivo que rompe con la dicotomía entre significante y significado, que lo vuelve experiencia estética viva, y por tanto, ética, en un mundo de perspectivas múltiples y simultáneas. En consecuencia, este modo de leer exige transformaciones en las estrategias pedagógicas de la lectura de los textos literarios en el aula de clase. Ó 
Bibliografía

Obras:

ADORNO, Teodor. Teoría Estética. Barcelona: Orbis, 1984.

BACHELARD, Gastón. Poética de la ensoñación. México: Fondo de Cultura Económica, 1993.

BORGES, Jorge Luis. Obra poética completa. Madrid: Alianza, 1989. Siete Noches. México: Fondo de Cultura Económica, 1986. Arte Poética. Trad. Justo Navarro. Barcelona: Crítica, 2001a. Obras completas. 4. vs. Buenos Aires: Emecé, 2001.

CERVANTES, Miguel de. Don Quijote de la Mancha 2v. Bogotá: Oveja Negra, 1983.

DERRIDA, Jacques. De la gramatología. Buenos Aires: Siglo XXI, 2003.

Cátedra, 1989. . Márgenes de la filosofía. Madrid: La escritura y la diferencia. Barcelona: Antropos, 1989a. . La diseminación. Madrid: Fundamentos, 1997.

La deconstrucción en las fronteras de la filosofía. Barcelona: Paidós, 1989b.

DESCARTES, Rene. Meditaciones metafísicas. Madrid: Alba, 1987.

ECO, Umberto. Lector in fabula. Barcelona, Lumen, 1992.

FOUCAULT, Michel. De lenguaje y literatura. Barcelona: Paidós, 1996. Entre filosofía y literatura. Barcelona: Piados, 1999. Las palabras y las cosas. México: Siglo XXI, 2001.

GADAMER, Hans Georg. Estética y hermenéutica. Madrid: Tecnos, 1996. Verdad y método I y II. Salamanca: Ediciones Sígueme, 1995. La actualidad de lo bello. Barcelona: Paidos, 1996 sa, 1995. Poema y diálogo. Barcelona: GediArte y verdad de la palabra. Barcelona: Paidos, 1998
¿Quién soy yo quién eres tú? Barcelona Herder, 1999.

HEGEL, Georg W. F. Lecciones de estética. 8 v. Buenos Aires: Siglo Veinte, 1984. . La poesía. Buenos Aires: Siglo Veinte, 1985a.

La idea de lo bello artístico o lo ideal. Buenos Aires: Siglo Veinte, 1983. La forma del arte romántico. Buenos Aires: Siglo Veinte, 1985b.

HEIDEGGER, Martín. Ser y tiempo. Madrid: Trotta, 2003.

Qué es metafísica. Buenos Aires: Siglo Veinte, 1988.

. De camino al habla. Barcelona:

Odos, 1990.

- Interpretaciones sobre la poesía de Hölderlin. Barcelona: Ariel Filosofía, 1983. Sendas Perdidas. Caminos de Bosque. Madrid: Alianza, 1996. Qué significa pensar. Paris: PUF, 1959.

Odos, 1996. Conferencias y articulos. Barcelona: Aportes a la filosofía. Acerca del evento. Buenos Aires. Biblos, 2003.

HUSSERL, Edmund. Ideas relativas a una fenomenología pura y una filosofía fenomenológica. México: F. C. E. 1985.

JAUSS, Hans Robert. Experiencia estética y hermenéutica literaria. Madrid: Taurus, 1992.

Pequeña apología de la experiencia estética. Barcelona: Paidós, 2002.

KANT, Emanuel. Critica del juicio. Madrid: Espasa Calpe, 1984.

LUCKACS, Georg. El alma y las formas. Barcelona: Grijalbo, 1985.

NIETZSCHE, Friedrich. Obras Inmortales $4 v$. Barcelona: Teorema, 1985.

PERCAS DE PONSETI, Helena. Cervantes y su concepto de arte. V II. Madrid: Gredos, 1975.

PLATON. República. Madrid: Espasa Calpe, 1984.

RICOEUR, Paul. Tiempo y narración. V. I. Madrid: Ediciones Cristiandad, 1987a.

Tiempo y narración. V. II. Madrid: Ediciones Cristiandad, 1987b. 
SXXI, 1996.

. Tiempo y narración. V. III. México:

SXXI, 1999.

Teoria de la interpretación. México:

. Historia y narratividad. Barcelona:

Paidós, 1999a.

RODRÍGUEZ P. J. ENRIQUE. Ensoñaciones, Escrituras, Tejidos. Debates Bachelard-Derrida. Bogotá: UNAD, 2003.

SZONDI, Peter. Poesía y filosofía de la bistoria. Madrid: Visor, 1992.

VAN DIJK, Teun. Texto y contexto. Madrid: Cátedra, 1988 .

. Las funciones del discurso. Mạdrid:

Catedra, 1988.

VATTIMO, Gianni. El fin de la modernidad. Barcelona: Gedisa, 1990.

Las aventuras de la diferencia. Pensar después de Nietzsche y Heidegger. Barcelona: Península, 1990. dós. 1989. Más allá del sujeto. Barcelona: PaiFilosofía y poesía: dos aproximaciones a la verdad. Barcelona: Gedisa, 1999. El pensamiento débil. Comp. Madrid: Cátedra, 2000.

WARNING, Rainer (ed.). Estética de la recepción. Madrid: Visor, 1989.

ZAMBRANO, María. Filosofía y poesía. México: Fondo de Cultura Económica, 2001.

\section{Artículos}

Allen, John J. "Narrator, the reader and Don Quijote". MLN, Vol. 91, No. 2, Hispanic Issue. (Mar., 1976), pp. 201-212. (http//links. jstor.org).

Cascardi, Anthony J. "Genre Definition and Multiplicity in Don Quixote". En: Cervantes: Bulletin of the Cervantes Society of America 6.1 (1986): 39-49. Copyright (C) 1986, The Cervantes Society of America.

"Cervantes and Descartes on the Dream Argument". En: Cervantes: Bulletin of the
Cervantes Society of America 4.2 (1984): 109-22. Copyright (C) 1984, The Cervantes Society of America

Maccurdy, Raimond R.; Rodríguez, Alfred. "Un momento de la creatividad cervantina en el Quijote: los capítulos XVIII-XXIII de la segunda parte". Hispania, Vol. 65, No. 3 (Sep., 1982), pp.395-400. (http//links.jstor.org).

Dunn, Peter N. "La cueva de Montesinos por fuera y por dentro: Estructura épica, fisonomía”. MLN, Vol. 88, No. 2, Hispanic Issue. (Mar., 1973), pp. 190-202. (http//links.jstor.org).

Durán, Manuel. "Perspectivismo en un capítulo del Quijote". Smith College. Hispania: Vol. 39, No., 2, (may, 1956), pp. 145-148. (http// links.jstor.org).

Sieber, Harry. "Literary Time in the "Cueva de Montesinos"'. MLN, Vol, 86, No. 2, Hispanic Issue. (Mar., 1971, pp. 268-273. (http// links.jstor.org).

Fry, Gloria M. "Symbolic Action in the Episode of the Cave o Montesinos from "Don Quijote”. Hispania, Vol. 48, No. 3. (Sep., 1965), pp. 468-474. (http//links.jstor.org).

Fucilla, Joseph G. “The Cave of Montesinos”. Italica, Vol. 29, No. 3. (Sep., 1952), pp. 170-174.

Núñez, María Gracia, "Ilusión y realidad en la cueva de Montesinos del Quijote" -n ${ }^{\circ} 24$ Espéculo (UCM) Revista de estudios literarios. Universidad Complutense de Madrid. El URL de este documento es http://www. ucm.es/info/especulo/numero24/cervantes. html. (C) María Gracia Núñez 2003

EI URL de este documento es

http://www.ucm.es/info/especulo/numero24/cervante.html

Percas de Ponseti, Helena, "La cueva de Montesinos", Revista Hispánica Moderna (Homenaje a Federico de Onís, I), XXXIV (1968), pp. 376-399.

"Unas palabras más sobre Belerma (Quijote II, 23)”. En: Cervantes: Bulletin of the Cervantes Society of America 19.2 (1999): 180-84. (http//links.jstor.org). 